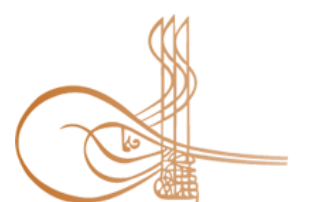

www.turkishstudies.net/economy
Turkish Studies - Economics, Finance, Politics

eISSN: $2667-5625$

Research Article / Araștırma Makalesi

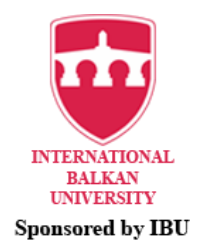

Sponsored by IBU

\title{
Su Üzerine Dünya İnşa Etmek: Küresel Sistemde Ekolojik Faktöre Bağlı Olarak Ulus- Devletlerin Geleceği; Kuzey Kutup Bölgelerindeki Buzul Erimesi Gerçeğii
}

\author{
Building the World on Water: The Future of Nation States in Global System Depending on the \\ Ecological Factor; The Glacial Melting Reality in the North Polar Regions
}

\author{
Bülend Aydın Ertekin ${ }^{* *}$ - Zeynep Ortakavak ${ }^{* * *}$
}

\begin{abstract}
Since the glacial melting due to global warming, which is one of the most important problems of our world, does not develop equally anywhere in the world, it is not perceived as a problem that directly affects the quality of life in everyday life. However, this problem is expected to show a profound impact on individuals in the medium and near future. The purpose of this study is to investigate the impact of this environmental event that affects the global system on the sovereign rights of countries. Within the scope of the study, the literature review is done, the data were examined and scenario maps were prepared within the framework of the data obtained from the data banks for the real situation caused by the rise of the sea level due to global warming and melting of the glaciers. Within the limits of the study, the scenario maps obtained from data banks and the countries and settlements that are emphasized are limited with certain examples. As a result of the study, it is seen that the rise of sea levels due to the melting of the glaciers means the loss of the territory and the right to sovereignty for some countries and settlements. It is expected that the socio-economic and cultural losses of the countries will increase intensely with the fact that this concrete event takes place effectively in certain parts of the world in the near future. Therefore, instead of waiting for the environmental consciousness to develop individually and institutionally, every country should start preventive practices and methods equally and simultaneously. In order to be successful against the negative factors caused by global warming, it will be useful to review the geopolitical concepts of the countries and to arrange the necessary measures according to the geo-climatic conditions.
\end{abstract}

Structured Abstract: Protecting the world's environmental future means protecting the nations, countries, and nation states that live in. The continuity of nation states is also linked to the continuity of sovereignty rights. States that lose their sovereignty naturally lose their influence, their claims on matters that have superiority and gradually their independence. A state and a nation can only speak of their existence with the concrete existence

\footnotetext{
${ }^{*} \mathrm{~B}$ ç̧alışmada Kuzey Kutup bölgesi ve senaryo haritalarının Arcgis programı ile düzenlenmesinde CBS uzmanı Zeynep Ortakavak katkı sağlamıştır.

** Doç.Dr., Anadolu Üniversitesi, İletişim Bilimleri Fakültesi, Basın ve Yayın Bölümü

Associate Professor, Anadolu University, Faculty of Communication Sciences, Journalism Department

ORCID 0000-0002-7578-0879

baertekin@anadolu.edu.tr

**** Doktora Öğrencisi, Anadolu Üniversitesi, Sosyal Bilimler Enstitüsü, Siyaset Bilimi ve Uluslararası İlişkiler ABD

PhD Student, Anadolu University, Graduate School of Social Sciences, Department of Political Science and International Relations

ORCID 0000-0002-9309-4792

zeyneportakavak@anadolu.edu.tr

Cite as/ Atıf: Ertekin, B., A. \& Ortakavak, Z. (2020). Su üzerine dünya inşa etmek: küresel sistemde ekolojik faktöre bağlı olarak ulus-devletlerin geleceği; kuzey kutup bölgelerindeki buzul erimesi gerçeği. Turkish Studies - Economy, 15(3), 1299-1325. https://dx.doi.org/10.47644/TurkishStudies.44724

Received/Geliş: 01 July/Temmuz 2020

Checked by plagiarism software

Accepted/Kabul: 20 September/Eylül 2020

Published/Yayın: 25 September/Eylül 2020

Copyright $(C)$ INTAC LTD, Turkey

CC BY-NC 4.0
} 
of the land in their possession. Many examples of civilizations which have lost their territory with infrastructure and substructure potential, with natural disasters, other than wars, are cited in the pages of history.

However, the problem of melting glaciers and global warming is linked to the world and its future not directly in history, but in its current state. As history repeats itself, the events illustrated by the history of the past represent a fact with which present and future generations will be confronted. It is also only possible for future generations to transfer their cultures from generation to generation by ensuring control of their sovereignty over a piece of territory. However, the loss of territorial land values with increasing seawater due to global warming and melting glaciers means that nations cannot transmit their cultural values.

Global warming issuing from human origin, the melting of glaciers due to global warming, the level of the sea level caused by the melting of glaciers, destroys the territory of the country, it also destroys the socioeconomic and cultural wealth of the nations of the region directly exposed to this problem. The socio-economic infrastructure and superstructures in the settlement units are on the verge of extinction.

In this context, this study focuses on the uncontrolled disturbance of the environmental balance of communities and societies with industrialization and production opportunities that have reached the targeted industrial and production stages. This environmental problem, which arose from the anxiety of producing and consuming more in its own production vortex, of societies with possibilities of industrialization and production, which can always achieve a higher level of the technological stages carried out during previous years, has now become natural, even if it has been issued from humans.

In this study, which focuses on this environmental problem, first of all, emphasis is placed on the importance of urgently taking human-induced measures (Here, the human does not mean the human being a simple creature. Before an individual human being, all precautions must be done by the state leaders, international organizations and multinational companies) to stop global warming and the melting of glaciers. The fact that scientists and research scientists have drawn attention to the importance of global warming and global warming since the 19th century has not prevented the problem from being resolved for the time being. The International efforts to prevent this environmental disaster are ineffective today, apart from the sensitivity of some individuals and non-governmental organizations.

The period of being sensitive and aware of this environmental problem is already over. In order to resolve this environmental problem and prevent the negative effects that continue and increase from day to day, the contribution and awareness of the responsibility of each country should be equal but proportional to the share of the countries which created this problem. The preventive measures to be taken by developed countries, responsible for global warming, should be taken on a larger scale.

However, developed, and industrialized countries, which have a significant share in this environmental problem, do not fulfill their own industrial, production and consumption restrictions on energy by ignoring the damage they have already done to the atmosphere. The recommendations and rules of the Kyoto Protocol and the Paris Climate Agreement are not taken into account. By the way, this study highlights this irresponsibility.

As part of the study, the data highlights the seriousness of this problem of rising sea levels due to global warming and the melting of the glacier. In addition, with the scenario maps organized according to the data, we can see how great the danger of this global environmental problem is.

Among the countries illustrated within the framework of the study, some examples are taken for such as : the Netherlands, although it is a small country in the world, whose socio-economic development has however high global income and standard of living, Bangladesh, a country suffering from socio-economic deprivation whose population lives on a narrow area, and finally Vietnam also presenting an example of a country in Southeast Asia, which has a population important when compared with that of European and Asian countries which attracts attention through its committed development movements.

Among the cities, Venice, which represents a European residential area with the cultural heritage of civilization that is going to have probably this environmental disaster in a century, and the city of Miami, which is an important residential and urban area for the United States, are they sampled separately on an urban basis. Of course, in addition to the examples given in the study, there are other examples that will experience the problem equally or slightly more or less damaged in the same geographic region. However, these examples were not given here within the limits of the study.

Turkish Studies - Economy, 15(3) 
As shown by the scenario maps and the study of the literature done as examples in the study, it can be seen that the developed and big states avoid taking initiatives despite the scientific importance attached to the measurement, research and observation of the problem of global warming and melting ice on the basis of day, week, month and year. This attitude of the big states makes this environmental problem more permanent and chronic for future generations.

If no action is taken in the near and intermediate future to resolve this environmental problem, the loss of territorial sovereignty of nation states that are in direct danger in the near and intermediate future will materialize. In the longer term, the number of countries affected by this global environmental disaster and its size in the world will increase.

Consequently, the loss of territorial sovereignty due to the rise in sea levels will not only lead to a loss of sovereignty. Each endangered nation state will face the loss of trillion dollars and social, economic, financial, technological and cultural infrastructure and, most importantly, a loss of human capital.

Since this danger will also trigger the immigration factor, mass migration to less problematic or more secure regions will lead to other regional, national or international confusion and problems.

Keywords: global warming, glacial melting, sea rise, sovereignty, environment

Öz: Dünyamızın en önemli problemlerinden biri olan küresel ısınmaya bağlı buzul erimeleri dünyanın her yerinde eşit bir şekilde gelişmediğinden ilk etapta gündelik yaşamda, yaşam kalitesini doğrudan etkileyen bir problem gibi algılanmamaktadır. Ancak bu problemin orta ve yakın gelecekte bireyler üzerinde etkisini derinden yoğun bir şekilde göstermesi beklenmektedir. Bu çalışmanın amacı, küresel sistemi etkileyen bu çevre olayının ülkelerin egemenlik haklarına etkisinin araştırılmasıdır. Çalışma kapsamında, literatür taraması yapılarak veriler incelenmiş ve küresel ısınma ve buzul erimesine bağlı deniz seviyesinin yükselmesinin yaratacağı reel durum için veri bankalarından elde edilen veriler çerçevesinde senaryo haritaları düzenlenmiştir. Çalışmanın sınırları kapsamında ise veri bankalarından elde edilen senaryo haritaları ve üzerinde vurgu yapılan ülke ve yerleşim birimleri belli örnekler ile sınırlandırılmıştır. Çalışmanın sonucunda, buzul erimesine bağlı deniz seviyelerinin yükselmesinin kimi ülkeler ve yerleşim bölgeleri için ülke toprağının ve egemenlik hakkının kaybolması anlamına geldiği görülmektedir. Bu somut olayın yakın gelecekte dünyanın belli yerlerinde etkin bir şekilde yaşanması ile ülkelerin sosyo-ekonomik ve kültürel kayıplarının da yoğun bir şekilde artması beklenmektedir. Bu yüzden, her ülkenin, çevre bilincinin bireysel ve kurumsal açıdan gelişmesini beklemesi yerine problemi önleyici uygulama ve yöntemleri eşit ve eş zamanlı olarak başlatması gerekmektedir. Küresel ısınmanın meydana getireceği olumsuz faktörlere karşı başarılı olabilmek için de ülkelerin jeopolitik konseptlerinin gözden geçirilmesi ve gerekli önlemlerin jeo-iklimsel şartlara göre düzenlenmesi yararlı olacaktır.

Anahtar Kelimeler: küresel ısınma, buzul erimesi, deniz yükselmesi, egemenlik, çevre.

\section{Giriş}

Fransızca halk deyimi ile "günü güne yaşamak" veya günlük ya da kısa vadelere dayalı üretilen siyasetlerin doğal olarak dünyanın gelecek nesillerini tam olarak düşünerek yapıldı̆̆ söylenemez. Devletlerin ve milletlerin en azından bin yıl ya da sonsuza kadar var olma idealinin gerçekleşmesi ancak devletlerin somut olarak dayandığı toprak ve onun üzerinde yaşayan millet (halklar) faktörlerine bağlıdır. Bir toprak parçası üzerinde yaşayan millet (halklar) sahip olduğu kültürü gelecek nesillere aktarabilme kabiliyeti ile varlığını sürdürmektedir. Bu kültürel kabiliyete sahip olan milletlerin (halkların) eğitim, sosyal, ekonomik, ticari, ideolojik, kültürel, teknolojik ve bilgi alanlarındaki birikimi, o milleti (halkı / halkları) diğerlerine oranla daha güçlü kılmaktadır. Bununla beraber, bu gücün devamlılığındaki temel esas devletin devamlılığında ana aktör olan milletin üzerinde yaşadığı toprak parçası ve bu toprağın çevre (environment) ekolojik sisteminin korunmasıyla da ilintilidir. Tarih, ekolojik sorunlar nedeniyle dünya üzerindeki kavimlerin /

${ }^{1}$ Vivre au jour le jour. 
milletlerin çaresiz bir şekilde anayurtlarını bırakarak göç etme zorunda kaldıklarına ilişkin örnekler ile doludur.

Aynı şekilde, eski kıta ülkelerindeki çevresel ve kentsel daralmadan kurtulma, zenginleşme veya kendilerini daha güven ve huzurda hissetme amacıyla yeni kıtalara göç edilerek o yeni toprak parçaları üzerinde yeni ülkelerin / birliklerin kurulması da bir bakıma çevre faktörüne bağlıdır. Geçmişte, göç edenlerin (göçmenlerin) sahip oldukları sınıf derecesine göre sınıf atlayarak sosyoekonomik zenginleşme ve refahlarını artırma idealinde itici ve katalizör rol oynayan faktör, bir yeni toprak parçası üzerinde daha geniş, daha fazla, daha bol, daha bereketli, daha güvenli ve daha rahat bir çevre içinde mülk edinme, zenginleşme veya yerleşme ideali şeklinde rol oynamıştır. Bu nedenle, çevresel zenginlik ve milletlerin içinde yaşadıkları çevre zenginliğine dayalı bölgesel güçleri birbiriyle orantılıdır. Bu bağlamda, küresel sistem içinde meydana gelecek olan ve çevre faktörlerini olumsuz etkileyecek olan her türlü çevresel problem doğrudan doğruya dünya ülkelerinin gelecekleri ve gelecek nesillerini tehdit etmektedir. Bu "tehdit" ve "gelecek" kavramları yakın bir gelecek için soyut gözükebilir olmakla birlikte eğer belli birikime sahip olan milletlerin kültürel yaşamlarının bir "android-insan" modelinden farklı sadece materyalist olmayıp kültürel boyutta da yaşamını sürdürmesi gerekli olan insan örneği şeklinde düşüldüğünde esasında çok da somut bir olayı teşkil etmektedir.

Örnek tahminler arasında, bir veya birkaç yüzyıl içinde, buzulların erimesiyle deniz seviyesinin yükselmesi nedeniyle günümüzde ülke topraklarının \%26'sı deniz seviyesinin altında olan, deniz üzerine toprak dolgusu ile oluşturulan alanlar ile coğrafi alan genişliği elde eden (Land Reclamation in the Netherlands 1300 Vs 2000 - Brilliant Maps, 2017) ve tarım ürünleriyle dünya ihracatında önemli bir gelir elde eden ufacık Hollanda (Viviano, 2017) gibi kıta Avrupa ülkesinin dışında okyanus üzerindeki mikro ada devletler toprak ve egemenlik kayıplarına maruz kalacaktır. Deniz sularının yükselmesiyle, Venedik gibi kültür ve turizme beldeleri de finansal ve ekonomik kayba uğrayacak ve ayrıca sular altında kalan kent yerleşimi olumsuz etkilenecektir.

Aslında, buzul erimesi ve buzul erimesini tetikleyen sorunların birlikte düşünülmesi gerekmektedir. Buzul erimesi dünya çevre faktörlerini olumsuz etkilemesinin ana nedeni olmasının yanında, erimenin oluşmasındaki faktörler de göz önüne alınmalıdır. Buzul erimesi küresel ısınmaya bağlıdır. Küresel ısınma da sanayileşme ve teknolojiden kaynaklanan sera gazları emisyonuna ve ozon tabakasının incelmesine bağlıdır. Sera gazları yoğunluğu ve ozon tabakasının delinmesi de ülkelerin sadece maddesel yaşam parçaları olan topraklarını değil aynı zamanda o toprakların üzerinde yaşayan insanların sağlık koşullarını ve yaşam kalitelerini de olumsuz etkilemektedir. Bunun yanı sıra, nüfus artışı, bilinçsiz kentleşme ve sosyo-ekonomik iş alanları için oluşturulan ticaret, sanayi, üretim ve enerji kaynaklarının konuşlandığı yapılaşma doğrudan doğruya insandan kaynaklanan olumsuz etkenlerdir. Bu yüzden buzul erimesindeki olumsuz itici gücün doğa faktörü değil insan olduğu görülmektedir. Buzul erimesi de doğrudan insanı dolayısıyla ulus-devletlerin sahibi milletlerin geleceğini olumsuz şekilde etkilemektedir. $\mathrm{Bu}$ açıdan bakıldığında, çevre faktörünün ulus-devletlerin geleceği açısından çok önemsenmesi gerekmektedir. Hatta dünya genelindeki insanlığın gözle görünmez düşmanı olan küresel salgınların, Birleşmiş Milletler ve Dünya Sağlık Örgütüne göre doğanın tahrip edilmesinden ileri geldiği ileri sürülmektedir (Carrington, 2020).

$\mathrm{Bu}$ çalışmada, Kuzey Kutup bölgesindeki buzul erimesinin ulus-devletlerin geleceğine ve ülkelerin egemenlik haklarının devamlılığına olası etkileri araştırılmıştır. Araştırma kapsamında, literatür taraması yapılmış, gerekli veriler incelenmiş ve veri bankalarından elde edilen veriler çerçevesinde senaryo haritaları düzenlenmiştir.

$\mathrm{Bu}$ çalışma beş aşamadan oluşmaktadır. Birinci aşamada, buzul ermesine yönelik farkındalığın tarihsel kronolojisi tanıtılmıştır. İkinci aşamada, buzul erimesi ve çevre duyarlılığına yönelik uluslararası resmi girişimler ele alındıktan sonra dünden bugüne kuzey- güney kutbu buzul 
erimesi sorunu üçüncü aşamada ele alınmıştır. Dördüncü aşamada, deniz seviyesinin yükselmesinin ülkelerin egemenlik haklarına "de facto" etkisi incelenmiştir. Son aşamada ise deniz seviyesinin yükselmesi durumunda tehdit altında bulunan bazı metropoliten şehirlerden örnekler verilmiş ve sonuç kısmı ile çalışma sonlandırılmıştır.

\section{Buzul Erimesine Yönelik Farkındalığın Tarihsel Kronolojisi}

Gümümüzde çevrecilik alanında birinci gündem maddesi olan dünyanın maruz kaldığ erime probleminin ele alınması çok eski yıllara dayanmaktadır. Buzul erimelerine ve 1S1 değişikliklerine ilişkin bilimsel çalışmalar bilimsel platformda 19.yüzyıldan itibaren bilim dünyasının çalışmalarında yer almıştır.

Encyclopedia of Global Warming \& Climate Change (Philander, 2012)'de yayınlanan kronolojiye göre; 1824'te Fransız matematik ve fizikçi Jean-Baptiste Joseph Fourrier atmosferdeki karbondioksit oranının artmasının iklim ısınması oluşturacağ 1 sonucuna varmıştır. 1859'da İrlandalı bilim insanı John Tyndall gaz yoğunlaşmasındaki değiş̧ikliklerin iklim değişliği getirebileceğini ileri sürmüştür. Bu konudaki çalışmalarını sürdüren Tyndall 1863 'te su buharlaşmasının sera gazlarından kaynakladığını bildirmiştir. 1875'te İngiliz bilim insanı James Croll buz ve karın güneş ışığını uzaya yansıttığını ve dünya 1sısında serinletme (soğutma) etkisi yaptığını kurgulamıştır. 1896'da İsveçli bilim insanı ve Nobel ödüllü Svente Arrhenius sera gazları kavramını kullanarak dünya ikliminin yavaş yavaş 1sındığını tahmin etmiştir. Arrhenius insan kaynaklı emisyonlardan küresel ısınmaya ilişkin ilk bilimsel hesaplamaları yayınlayan kişidir. 1897'de İngiliz bilim insanı Thomas C. Chamberlin küresel 1sınma ve yüksek karbondioksit yoğunlaşması ve buzul çağı ve düşük yoğunlukta karbondioksit yoğunlaşması arasındaki bağları ortaya koymuştur (Philander, 2012: xxxvi-xxxvii). 1910'da İsveçli kimyager Svante Athenius ilk defa olarak dünya gezegenindeki ısınmanın atmosferde devamlı artan sanayi gazına bağlı olduğu hipotezini formüle etmiştir. Diğer öncüler arasında, 1926'da biyolog Vladimir Vernadsky ve 1950'lerde ekonomist Kenneth Boulding insan kaynaklı faaliyetlerin çevre üzerindeki etkileri konusunda geniş araştırmalar yapmışlardır (Ramonet, 2005: 6). Daha 1938'lerde bilim adamı G. S. Callendar Kuzey Kutbu'nda hava sıcaklığında artış olduğunu bunun da sera gazları etkisiyle oluştuğunu söylemiştir.1950'lerde ise Amerikalı bilim insanı Charles F. Brooks Kutuplardaki ısınmaya bağlı deniz seviyesinin artışına vurgu yapmıştır (Philander, 2012: xxxvii). Bunların dışında çevre bilincin artması ve kamuoyu yaratmada öncü olan bilimsel tarım uzmanı (agronom) René Dumont 1974'deki görsel röportajında "Gezegenimizin tamamen çöküşüne doğru gidiyoruz" (1974: René Dumont "Nous allons à l'effondrement total de notre planète 》| Franceinfo INA - YouTube, 2019) tezini ileri sürmüştür.

Kronolojik olarak incelendiğinde, 19.yüzyılın başından başlayan ve 1950'li yıllarda aşama kaydederek ilerleme kaydeden bilim insanlarının yakın gelecek ve gelecekte bir tehdit oluşturan buzul erimeleri konusundaki çalışmaları günümüze kadar devam etmiştir ve etmektedir. ${ }^{2}$

\section{Buzul Erimesi ve Çevre Duyarlılığına Yönelik Uluslararası Resmi Girişimler}

Atmosferdeki karbondioksit seviyesi 1960'ta 315 ppm iken bu değer 2009 yılında yapilan ölçümlerde 'da 385 ppm değere yükselmiştir (Philander, 2012: xlii). Bilim adamlarının sadece ortaya koyduğu hipotezler ve çalışmalar ile değil resmi ve uluslararası kuruluşların konuya gösterdiği önem de gün ve gün artmaktadır. Ancak ortaya konan resmi ve uluslararası raporların yayınlanması sadece konu hakkında bilimsel bilgilenme sağlamaktadır. Oysa, ortaya konan bu raporların amacı Birleşmiş Milletler üyesi ülkelerin üzerlerine düş̧en sorumluluklarını yerine getirmesi ve harekete geçmesidir. Doğal olarak, ülkelerin buzul erimesini tetikleyen atmosferde yoğunlaşan sera gazları oranlarındaki sorumluluk payı eşit değildir. Bu payda eşit sorumluktan ziyade, buzul erimesine olumsuz etki yapan

\footnotetext{
2 Önceki çalışmalar bir baz oluşturduğundan, çalışmanın sınırları kapsamında 1950’lerden günümüze kadar bilimsel çalışmaları ile katkı yapan bilim insanlarının buzul erimesi ile ortaya koydukları hipotezler ve analizler ile literatüre katkı yapan bilim insanlarının adlarına yer verilmemiştir.
} 
ve atmosferdeki sera gazları oranındaki payları çok daha büyük olan sanayileşmiş ve gelişmiş ülkelerin atmosfere verdiği zarar paylarına göre davranmaların beklenmesidir. Bu tür bir eylemin tüm tedbirler uygulanarak uygulamaya konması şimdilik gelişmiş, sanayileşmiş ülkeler tarafinda bir ütopi olarak kalmaktadır. Atmosfer sera gazları emisyonunda yüksek paya sahip ABD ve diğer G-7 gelişmiş ülkeleri dışında, diğer taraftan, 2001'de DTÖ üyesi olarak küresel ticaret entegrasyonuna katılarak küresel bir sanayi gücü olmaya çalışan Çin'in sorumluluk payı bulunmaktadır. Çin'in yanı sıra Rusya, Hindistan, Brezilya gibi yeterli çevre kontrolüne sahip olmadan küresel liderlikten pay almaya çalışan ancak sanayi tesislerinin sahip olduğu teknoloji düzeyinin yeterince çevreye duyarlı olmaması nedeniyle atmosfere sera gazları yayan sorumlu ülkeler olarak sıralanabilir.

1970'lerden itibaren özellikle gelişmiş olan ülke kamuoyu resmi raporların etkisiyle, çevre sorunlarına ilgi duymaya başlamıştır. İlk Dünya Günü 1970'te kutlanmıştır (Philander, 2012: xxxviii). 5-16 Haziran 1972'de Birleşmiş Milletler İnsan Çevre Konferans1 (Stockholm Konferans1) küresel boyuttaki tüm çevre sorunlarına dikkat çeken bir rapor yayınlamıştır. Bu konferans milat kabul edilerek 5 Haziran Dünya Çevre Günü ilan edilmiştir (Report of the United Nations Conference on the Human Environment, 1972: 32). Ayn tarihlerde 5 Haziran 1972'de ise genel merkezi Kenya, Nairobi'de Birleşmiş Milletler Çevre Programı (Programme des Nations unies pour l'environnement) faaliyete geçmiştir. Bu program çerçevesinde oluşturulan Dünya Çevre ve Kalkınma Komisyonu (the World Commission on Environment and Development / WCED) Nisan 1987'de yayınladığı Ortak Geleceğimiz (Our Common World) raporu, Kuzey Amerika'da çok etkin olmakla birlikte, Avrupa'da gereken dikkati çekmemiştir (Report of the World Commission on Environment and Development: Our Common Future, 1987).

Fransa'da ise Kanada Kebekli (Québecois) editörlerin bu raporu "Notre avenir à tous" başlığı ile Fransızca' ya çevirmesi bir bilinçlenme ve duyarlılık yaratmıştır. 1988'de Le Monde diplomatique'deki yazısında bu rapora da atıfta bulunan René Dumont "Yağmalanan Gezegen: İnsanların hayatta kalması büyük tehlike altında" başlıklı yazısında, deniz suyu kütlelerinin sürekli 1sınması kutup buzullarının erimesine, eriyen buzullar okyanus seviyesinin yükselmesine etki yapacak ve bu durum ise dünya nüfusunun üçte birinin yaşadığg dünyadaki tüm liman tesisleri, vadiler ve kıyı bölgelerini tehdit edeceğini hem yazar hem de bilim insanı sıfatıyla belirtmiştir (René Dumont, Octobre 1988:11-12).

1980'de Doğa ve Doğal Kaynakların Korunması için Uluslararası Birliği (the International Union for Conservation of Nature and Natural Resources / IUCN), Birleşmiş Milletler Çevre Programı (the United Nations Environment Programme / UNEP ) ve Dünya Doğayı Koruma Vakfi (the World Wildlife Fund / WWF) tarafindan organize edilen Dünya Koruma Stratejisi (the World Conservation Strategy / WCS)'nin yayınladığ 1 raporda sürdürebilir kalkınmanın yaşayan kaynakların korunması ile gerçekleştirilmesi gelişmiş ve gelişmekte olan ülkelere tavsiye edilmiştir (World Conversation Strategy: Living Resources Conservation for Sustainable Development, 1980:IV). Dünya Koruma Stratejisi'nin çevresel bilinçlenme ve kamuoyu oluşturulması için yaratılan logoda (Resim 1) birbirine kenetlenen, çakışan üç ok, süreçler ve yaşam destek sistemleri, genetik çeşitliliğin korunması ve türlerin sürdürülebilir kullanımını ve ekosistemlerin korunmasını sembolize ederken dış yüzeydeki daire ise dünya gezegenini kaplayan ince biyosfer örtüsünü tanımlamaktadır (World Conversation Strategy: Living Resources Conservation for Sustainable Development, 1980). 
Logo 1: Dünya Koruma Stratejisi Logosu

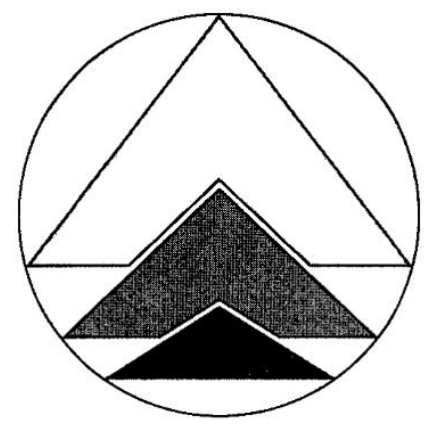

Kaynak : (World Conversation Strategy: Living Resources Conservation for Sustainable Development, 1980:1)

Bununla beraber, 1980'lerde ABD'de küresel 1sınma hakkındaki bilgiler siyasi muhafazakâr şüphecilikle bağlantılı kalmıştır. Örneğin bu bilinçsiz tepkinin, Ronald Reagan'ın başkan olarak seçilmesinde rolü olmuştur (Philander, 2012: xxxix).

1992'de Rio'da Dünya Zirvesi'nde ABD çevre konusunda inisiyatif almama kararına varmıştır. 1995 Berlin toplantısında ise çıkan karar 1997'de Kyoto' da konunun ele alınması dileğiyle sonlanan bir zirve olmuştur. Bir bakıma sera gazları emisyonunun atmosfere, çevreye ve buzullara verdiği zararların önlenmesi için tavsiye niteliğinde kararların alınması uluslararası bazda 10 Aralık 1997 Kyoto protokolü ile olmuştur. Kyoto Protokolü'nde farklı seviyelerde gaz emisyonu sınırlamas1 için gelişmiş ülkeler taahhütte bulunmuştur. Bunlar arasında, ABD \%7, Avrupa \%8 Japonya \%6'l1k bir emisyon azaltmasını taahhüt ederken, Avustralya için ise \%8'lik bir artırım öngörülmüştür. Bu hedeflerin 2008-2012 yılları arasında gerçekleşmesi planlanmıştır (Chemillier-Gendreau, 1998: 3). 1997'de imzalan Kyoto Protokolü 2005'de yürürlüğe girmiş olmasına rağmen, özellikle ABD protokolü onaylamamış ve kararlarına uymamıștır (Philander, 2012: xlii). ABD'nin yanı sıra, 2011 'de Kanada (Canada pulls out of Kyoto Protocol | CBC News, 2011) ve Rusya (Astrasheuskaya, 2012) Kyoto protokol hükümlerinden çekileceklerini açıklamışlardır. Japonya 2002'de protokolü onaylamış olsa da daha sonra ek protokole uymayacağını belirtmiştir (Written question - Withdrawal of Japan from the Kyoto Protocol - E-000290/2013, 2013). 2016'da ise tek imzacı ülke olarak kalan ABD protokolü onaylamamıştır. Kyoto Protokolü'nün dışında küresel ısınma ve çevre sorunlarının çözümü için diğer emsal bir uluslararası çaba 200 ülkenin iştiraki ile 2015'de imzalan ve 2020'de yürürlüğü giren Paris İklim Sözleşmesi'dir (The Paris Agreement | UNFCCC, 2015). Ancak Trump ABD başkanı olduktan sonra, her firsatta ABD'nin egemenlik hakkını çiğnetmeyeceğini belirterek, Paris Sözleşmesinden çekilme kararı almıştır (Green, 2019). Oysa Tablo 1 ve Tablo 2 örneklem kapsamında seçilmiş ülkelerin atmosfere verdiği zararı göstermektedir. Tablolardan anlaşılacağı üzere, emisyon oranları ciddi boyuttadır, ancak ülkeler somut sorumluluk almaktan kaçınmaktadırlar. 
Tablo 1: Seçilmiş Ülkelerin 1960-2014 Yılları Arasındaki CO2 Emisyonu (kişi başına metrik ton)

\begin{tabular}{|c|c|c|c|c|c|c|c|c|}
\hline Ülkeler & 1960 & 1970 & 1980 & 1990 & 2000 & 2010 & 2013 & 2014 \\
\hline $\mathrm{ABD}$ & 15,9998 & 21,1113 & 20,7865 & 19,3228 & 20,1788 & 17,4431 & 16,3268 & 16,5073 \\
\hline Almanya & & &.. & & 10,0956 & 9,27963 & 9,39062 & 8,88937 \\
\hline Birleşik Krallkk & 11,1508 & 11,7324 & 10,2868 & 9,71088 & 9,19955 & 7,85784 & 7,14584 & 6,49853 \\
\hline Brezilya & 0,64989 & 0,98579 & 1,55012 & 1,4019 & 1,87644 & 2,14474 & 2,50541 & 2,61293 \\
\hline Çin & 1,17038 & 0,94293 & 1,49525 & 2,15157 & 2,69686 & 6,56052 & 7,55721 & 7,54391 \\
\hline Fransa & 5,81744 & 8,44943 & 9,16153 & 6,45122 & 5,94667 & 5,42898 & 5,06217 & 4,57346 \\
\hline Hindistan & 0,26763 & 0,35149 & 0,44927 & 0,709 & 0,9766 & 1,39327 & 1,5886 & 1,72767 \\
\hline İtalya & 2,17844 & 5,51339 & 6,89248 & 7,3617 & 7,91267 & 6,83837 & 5,73294 & 5,27087 \\
\hline Kanada & 10,7708 & 16,0141 & 18,0796 & 15,7155 & 17,4146 & 15,7233 & 14,7411 & 15,1589 \\
\hline Rusya & 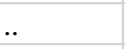 & 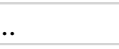 & 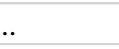 & $x=$ & 10,6271 & 11,6943 & 12,3936 & 11,8575 \\
\hline Suudi Arabistan & 0,65506 & 7,76013 & 17,4797 & 11,4455 & 14,3698 & 18,9082 & 18,0034 & 19,4407 \\
\hline
\end{tabular}

Kaynak: Tablo 1. World Development Indicators | DataBank. (2020). The World Bank. https://databank.worldbank.org/reports.aspx?source=2\&series=EN.ATM.CO2E.PC\&country=\# 'den elde edilen veriler ile düzenlenmiştir.

Grafik 1'de görüldüğü gibi, 2014 yılında Suudi Arabistan kişi başına düşen metrik ton oranı en fazla gözüken ülkelerin başında gelmektedir. Ancak Suudi Arabistan'ın diğer ülkelere göre daha düşük olan nüfus oranında da burada dikkate alınması gerekmektedir. Değerler arasında, ABD, Kanada ve Rusya diğer önemli oranlara sahip olan ülkeler arasında sıralanmaktadır. İngiltere ve Çin'in değerleri de küresel ısınma ve buzul erimesinde payları vardır.

Grafik 1: Seçilmiş Ülkelerin 2014 Y1lı CO2 Emisyonu (kişi başına metrik ton / \%)

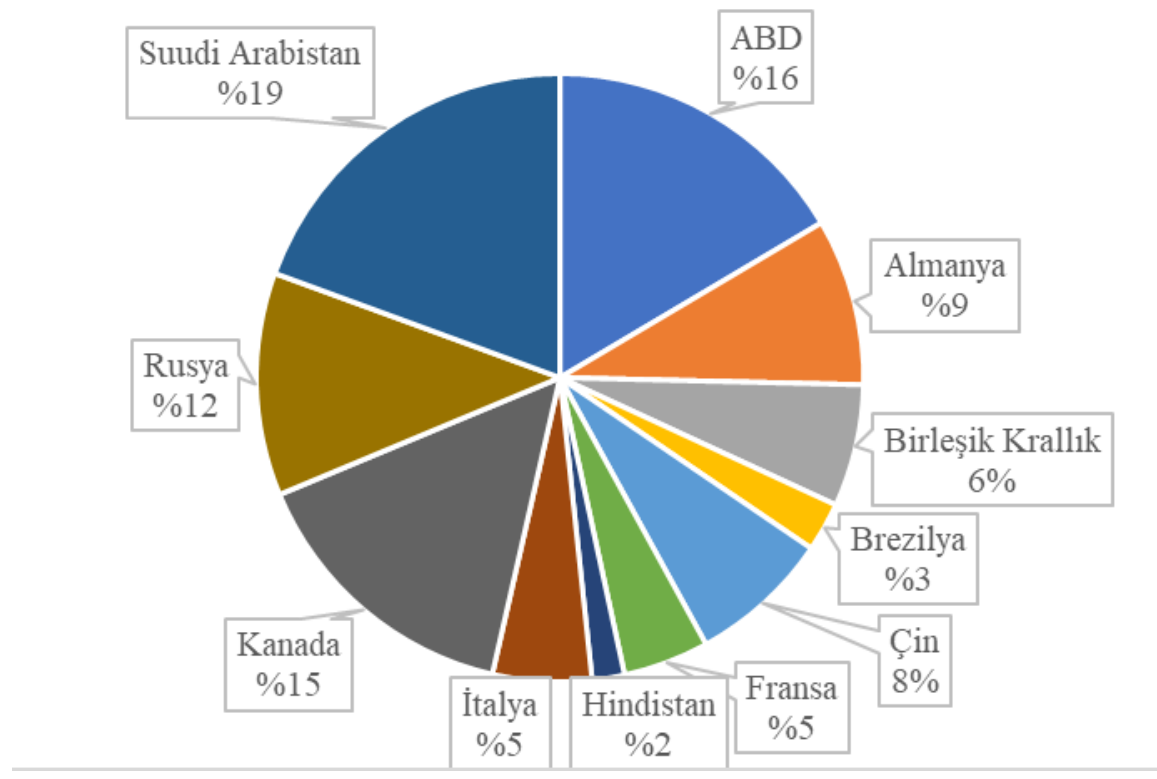

Kaynak: Grafik 1. World Development Indicators | DataBank. (2020). The World Bank. https://databank. worldbank.org/reports.aspx?source=2\&series=EN.ATM.CO2E.PC\&country=\# 'den elde edilen veriler ile düzenlenmiştir. 
Tablo 2: Seçilmiş Ülkelerin 1990- 2012 Y1lları Arasındaki Toplam Sera Gazları Emisyon Oranı (kt CO2 eşdeğeri)

\begin{tabular}{|l|r|r|r|r|r|}
\hline Ülke & 1990 & 2000 & 2010 & 2011 & 2012 \\
\hline ABD & $6.136 .093,50$ & $6.969 .123,80$ & $6.713 .348,97$ & $6.571 .653,98$ & $6.343 .840,51$ \\
\hline Almanya & $1.256 .074,03$ & $1.016 .295,55$ & $948.006,75$ & $929.540,26$ & $951.716,71$ \\
\hline Birleşik Krallk & $777.244,23$ & $673.897,41$ & $609.586,56$ & $568.061,83$ & $585.779,78$ \\
\hline Brezilya & $1.606 .209,33$ & $1.222 .630,43$ & $2.902 .242,62$ & $2.953 .040,52$ & $2.989 .417,96$ \\
\hline Çin & $3.892 .675,16$ & $5.082 .325,60$ & $11.183 .810,60$ & $12.064 .260,00$ & $12.454 .710,61$ \\
\hline Fransa & $554.685,28$ & $559.922,20$ & $532.133,04$ & $502.656,65$ & $499.146,63$ \\
\hline İtalya & $508.764,94$ & $547.349,86$ & $489.460,13$ & $482.619,04$ & $482.634,00$ \\
\hline Kanada & $608.685,00$ & $760.643,00$ & $764.137,68$ & $1.033 .481,98$ & $1.027 .063,85$ \\
\hline Rusya & $3.593 .581,92$ & $2.771 .222,00$ & $2.603 .289,63$ & $2.777 .724,31$ & $2.803 .398,49$ \\
\hline Suudi Arabistan &. & $310.713,50$ &.. & $514.967,26 .$. \\
\hline
\end{tabular}

Kaynak: Tablo 2. Total Greenhouse Gas Emissions / World Development Indicators | DataBank. (2020). The World Bank.

https://databank. worldbank.org/reports.aspx? source=2\&series=EN.ATM.GHGT.KT.CE\&country=\#' 'den elde edilen veriler ile düzenlenmiştir.

Grafik 2'de 2012 yılında sera gazları dünya toplamı en fazla emisyon değeri \%44 ile Çin'e aittir. \%22 pay ile ABD ikinci sırada gelmektedir. Çin ve ABD'nin dışında, toplam sera gazları emisyonu ile küresel ısınma ve buzul erimesine olumsuz etki eden ülkeler arasında Brezilya'nın payı $\% 11$ ve Rusya'nın \%10'dur. Toplam değerlerde ise Kanada \%4, Almanya \%3 ve Birleşik Krallık $\% 2$ 'i temsil etmektedir.

Grafik 2: Seçilmiş Ülkelerin 2012 Y11 Toplam Sera Gazları Emisyon Oranı (kt CO2 eşdeğeri)

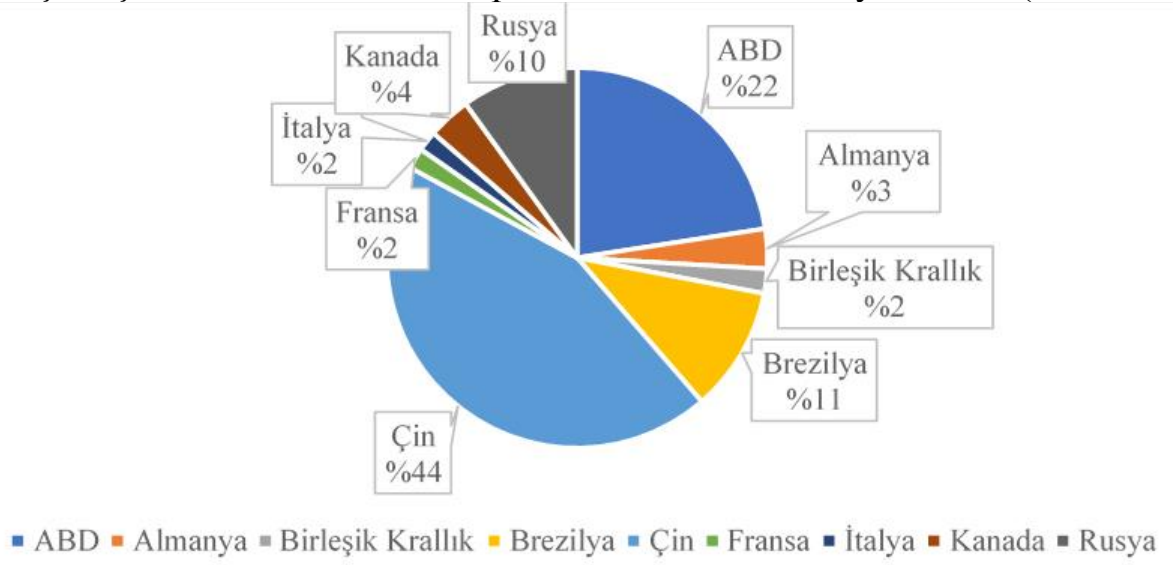

Kaynak: Grafik 2. Total Greenhouse Gas Emissions / World Development Indicators | DataBank. (2020). The World Bank.

https://databank. worldbank.org/reports.aspx? source=2\&series=EN.ATM.GHGT.KT.CE\&country=\# 'den elde edilen veriler ile düzenlenmiştir.; Suudi Arabistan'ın 2012 verisi olmadığı için grafikte belirtilmemiştir.

\section{Dünden Bugüne Kuzey- Güney Kutbu Buzul Erimesi Sorunu}

Kuzey kutbunda denizyolu ulaşım ve nakliyatçılığı açısından yeni denizyollarının açılması ve Kuzey Amerika ve Sibirya'daki hidrokarbürün yataklarının erişimine imkân sağlayacağı yönünde ileri sürülen olumlu yaklaşımlara rağmen buzulların erimesi öncelikle mevsimsel hava ve isı değişimlerine neden olmaktadır. Devam eden erime nedeni ile Kuzey kutbu buz kütlelerinin 
yüzölçümü otuz yıl içinde $\% 10$ azalarak kütle kalınlığ1 \%40 oranında incelmiş olacaktır ( $L^{\prime}$ Atlas $d u$ Monde diplomatique, 2006: 12).

$\mathrm{Bu}$ süreç doğal olarak günümüzde birdenbire başlamış bir süreç değildir. Ancak sanayileşmenin, doğanın tahrip edilmesi, kentleşmenin ve ulaşım araçlarının neden olduğu ölçüsüz ve kontrolsüz sera gazları emisyonu dolayısıyla ozon tabakasının incelmesi, küresel ısınma gibi etkiler ile buzulların erimesi dereceli devam etmektedir. Olumsuz etkenler arasında yer alan sera gazlarına bağlı küresel ısınma buz erimesini arttırmaktadır (Mathez ve Smerdon, 2018:5).

130.000 y1l önce de iklim günümüzden daha sıcaktı ve buz kütlelerinin erimesiyle 18 metreye ulaşan deniz seviyesi bugünden daha yüksek idi (Philander, 2012: xxxvi ). Bu somut olay, buzulların erimesi durumunda, deniz seviyesinin nasıl yükseleceğini ve yerleşim birimlerinin sular altında kalacağının coğrafi ve iklim bilimleri açısından anlatan önemli bir örnektir. Bir bakıma, küresel 1sı değerlerinin artması ya da buzul iklimi etkisi yaratacak şekilde eksilmesi de insan ve doğanın yaşamında hassas bir denge oluşturmaktadır.

Bu hava sıcaklığı dengesinin önemine ilişkin yakın tarihten iki farklı döneme ilişkin örnek bulunmaktadır. Birinci örnek, 900-1300'lü yılları kapsamaktadır. Bu dönemde uygun 1lıman hava koşulları sayesinde çiftçiler bol ürün almışlardır. Ilıman hava sıcaklıkları ve bol tarım ürünlerine bağlı olarak aynı zamanda bu dönemde dünya insan nüfusu artmıştır. Diğer bir örnek ise, Küçük Buz Çağı olarak tanımlanan 1400-1840'lı yılları kapsamaktadır. Bu dönemde rekor seviye soğuk hava sıcaklığı ve kar yağışlarının etkisiyle hastalık, ölüm ve açlık oranları artmıştır. Bu dönem ile karşılaştırıldığında, günümüzde sera etkisinin neden olduğu küresel 1sınmaya ilişkin yapılan tahminlerin, Küçük Buzul Çağı'nın sona ermesinden bu yana dünyanın en hızlı 1sınma dönemi olacağ1 yönünde hesaplanmaktadır (Philander, 2012: xxxvi).

Buzul erimesi 1sınmayı hızlandıracak ve normalde buzullarda \%80, çıplak kara parçası üzerinde $\% 30$ ve denizde $\% 7$ etkisi olan güneş radyasyonunun kırılma seviyesini azaltacaktır (L'Atlas du Monde diplomatique, 2006:12). Buz, kara ve sudan çok daha fazla yansıtma özelliğine sahiptir. Bu kırılma gücünün azalması nedeniyle güneş ışığının yansıtılması yerine karasal alanlarda emilecek olması, kutuplarda çok daha fazla erimeye neden olacaktır (Philander, 2012: 1165).

Topex-Poséidon uydu ölçümlerine göre deniz seviyesi yılda 2,4 mm artmaktadır. Bu oran 22.yüzyılın başında dünya genelinde en azından $25 \mathrm{~cm}$ 'lik bir yüksekliğe ulaşacaktır ( $L^{\prime} A t l a s ~ d u$ Monde diplomatique, 2006:13). Buzulların erimesi küresek ekolojik bir problem olmasına rağmen, bu amaçla kurulmuş olan Kuzey Kutbu Konseyi ( le Conseil de l'Artique) üyeleri Amerika Birleşik Devletleri, Kanada ve Çin gerekli olan somut adımları atmak için anlaşamamaktadırlar ( L'Atlas du Monde diplomatique, 2006:12). Ancak konunun hassaslığı uluslararası değişik platformlarda ele alınmaktadır. Bu konuda değişik projeksiyonlarda yapılmaktadır. Örneğin 2001'de İklim Değişikliği Hükümetlerarası Paneli (the Intergovernmental Panel on Climate Change / IPCC)'in 2001 raporunda 1990-2100 yılları arasında deniz seviyesinin yüksekliğinin 9 ile $88 \mathrm{~cm}$ arasında yükseleceğini ve küresel yüzey sıcaklığının da 1.4 ile $5.8 \mathrm{C}$ derece arasında artacağı tahmininde bulunmuştur. $\mathrm{Bu}$ tahmin, IPCC'nin 2007 'de yayınladığ 1 farklı senaryolara dayalı raporunda ise, 21.yüzyılın sonunda, büyük nüfuslu alçak konumdaki kıyı şeritleri deniz seviyesinin artmasından etkilenecektir. 2099 yılına kadar deniz seviyesi artışının $0.18 \mathrm{~mm}$ ile $0.59 \mathrm{~mm}$ arasında olacağı şeklinde revize edilmiştir (Philander, 2012: 1242).

Deniz seviyesinin artması dünyanın her yerinde aynı ölçüde olmamakla birlikte (Mathez ve Smerdon, 2018: 307) küresel bir problem olarak an ve an sürmektedir. 1993-2010 y1lları arasında sadece okyanusların termal 1s1 genişliği ile yılda ortalama $1.1 \pm 0.3 \mathrm{~mm}$ oranında bir yükselme olmuştur. Bu yükselme 1971-2010 arasında öngörülen tahminlerden fazla olmuştur (Mathez ve Smerdon, 2018: 311). 
Okyanusların termal genişlemesinden, buzulların ve buz örtülerinin erimesi, Grönland ve Antarktika buz tabakalarının erimesi, karasal depolamalardaki değişiklikler deniz seviyesinin yükselmesinde etkin rol oynayan en önemli etkenler olarak sıralanmaktadırlar (Philander, 2012: 1242-1243).

Ülkeler açısından bu sorun çok önem ihtiva etmektedir. Bu durumun kontrol edilememesi neticesinde, örneğin yarım metrelik deniz seviyesinin yükselmesi Bangladeş'in \%10'luk yaşanabilir arazisinin sular altında kalmasına ve 6 milyon insanın bu durumdan olumsuz etkilenmesine neden olacaktır. Bir metrelik deniz seviyesindeki yükselmesi ise ülkenin \%20'sini etkileyerek 15 milyon insanın sular altında kalması ile sonuçlanacaktır (Radford,2004'den aktaran Johansen, 2017:282 ; Radford, 2004).

Su altında kalma riski Pasifik ada devletlerini ise çok daha tehlikeli bir biçimde tehdit etmektedir. İklim değişiklerinden meydana gelen tropikal seller özellikle Hindistan ve Bangladeş’te yıkıcı etkiler yapmaktadsır. Örneğin iklim değişikliklerinin meydana getirdiği tropikal kasırgalar insanları ve yaşam ve tarım alanlarını yok etmektedir (Climate refugees in Bangladesh $\mid D W$ Documentary - YouTube, 2019).

1998'deki El- Niño kasırgası bazı ufak Pasifik adalarını yutmuş ve içme su rezervlerini kirletmiştir. Buzul erimelerinden ve buzul erimelerinin tetiklediği olumsuz etkenler dolayısıyla Okyanuslar da artık ada devletler için bir jeopolitik dost değil jeopolitik düşman haline dönüşmektedir. Bunlar arasında Tuvalu, Kiribati ve Kiribati'ye bağlı Tebua Tarawa doğrudan etkilenen bölgelerdir (Johansen, 2017:284).

Buz tabakalarının erimesine ve kütlelerin incelmesine ilişkin aşağıda yer alan grafikler 1979'dan itibaren y1l ve yıl buz kütlelerinin incelme oranını göstermektedir.

Küresel 1sınmaya ilişkin yapılan senaryolara göre küresel ısınmadan en çok Kuzey küre bölgesi etkilenecektir. $2{ }^{\circ} \mathrm{C}^{\prime}$ lik hava sıcaklığı artışı, Kuzey bölgesini iki veya üç kat daha fazla etkileyecektir. Güney kürede ise bu etkinin daha az olacağı tahmin edilmektedir ( $L$ 'Atlas du Monde diplomatique, 2006: 12). Ancak hava sıcaklığı artışları senaryolardan öte gerçek bir durum almış bulunmaktadır. Kuzey Kutbu'nda bulunan meteoroloji istasyonu görevini icra eden Kanada askeri üssü ALERT 14 Temmuz 2019 tarihinde hava sıcaklığını $21^{\circ} \mathrm{C}$ olarak ölçmüştür. Bu değer ortalama normal değerden 15 derece fazla bir değerdir. Hükûmetler arası İklim Değişikliği Paneli (Le Groupe d'experts intergouvernemental sur l'évolution du climat / GIEC), Kuzey Kutbu'nda zaten $1{ }^{\circ} \mathrm{C}$ olarak tahmin edilen değer daha fazla küresel ortalamanın iki ila üç katı daha yüksek değerlerde bir küresel 1sınmanın olduğunu ortaya koymaktadır (Baccaro ve Descamps, 2020:14-15). 22 Haziran 2020 tarihinde ise Sibirya' da $67^{\circ}$ kuzey enleminde bulunan Verkhoïansk şehrinde hava sıcaklığ 17 derece fazla olarak $38^{\circ} \mathrm{C}$ 'ye erişmiştir ("Il a fait $38^{\circ} \mathrm{C}$ en Sibérie : record de température au-delà du cercle arctique," 2020); À la conquête des océans polaires, 2020).

Grafik 3, Grafik 4 ve Grafik 5'te küresel ısınmanın yaptı̆̆ tahribatlar açıcça görülmektedir. Grafik verilerinin ortaya koyduğu gibi, Kuzey Kutbu buzlu kütlelerinde 1979'dan 2019'a kadar kademeli incelme görülmektedir. Grafik verilerinde, Kuzey konumu 9.ay (Eylül ayı), buz kütlelerinin etkilendiği bölge sınırı (extend) ve alan (area) gösterilmiştir. Grafik 3'te 1979 yılı bölge sınırı 7,05 milyon $\mathrm{km}^{2}$ ve alan 4,58 milyon $\mathrm{km}^{2}$ iken bu oran 1990 yılında bölge sınırının 6,14 milyon $\mathrm{km}^{2}$ ve alanın 4,55 milyon $\mathrm{km}^{2}$ değerine düşmesi ile sonuçlanmıştır. 


\section{Grafik 3 Kuzey Kutbu 1979-1990 Verileri (Milyon km²)}

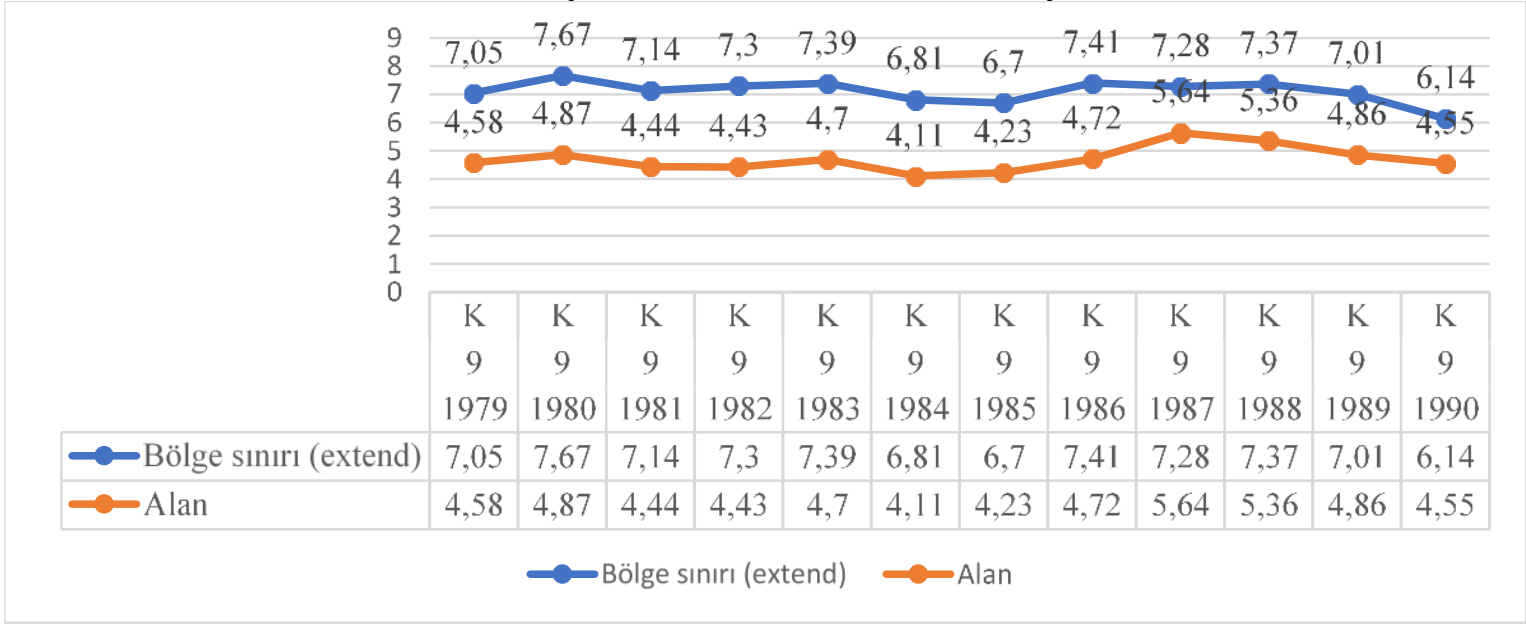

Kaynak: Grafik 3. Arctic Sea Ice Minimum | Vital Signs - Climate Change: Vital Signs of the Planet. (2020). NASA / Global Climate Change. https://climate.nasa.gov/vital-signs/arctic-sea-ice/ 'den elde edilen veriler ile düzenlenmiştir.

Grafik 4 değerleri 1991-2003 yıllarını göstermektedir. 1991 yılında 6,47 milyon $\mathrm{km}^{2}$ 'ye çıkan bölge sınırı değeri 2003 'te 6,12 milyon $\mathrm{km}^{2}$ 'ye ve 1991 'de 4,51 milyon $\mathrm{km}^{2}$ 'ye düşen alan değeri 2001 'de daha düşerek 4,05 milyon $\mathrm{km}^{2}$ 'ye inmiştir.

\section{Grafik 4 Kuzey Kutbu 1991-2003 Verileri (Milyon km²)}

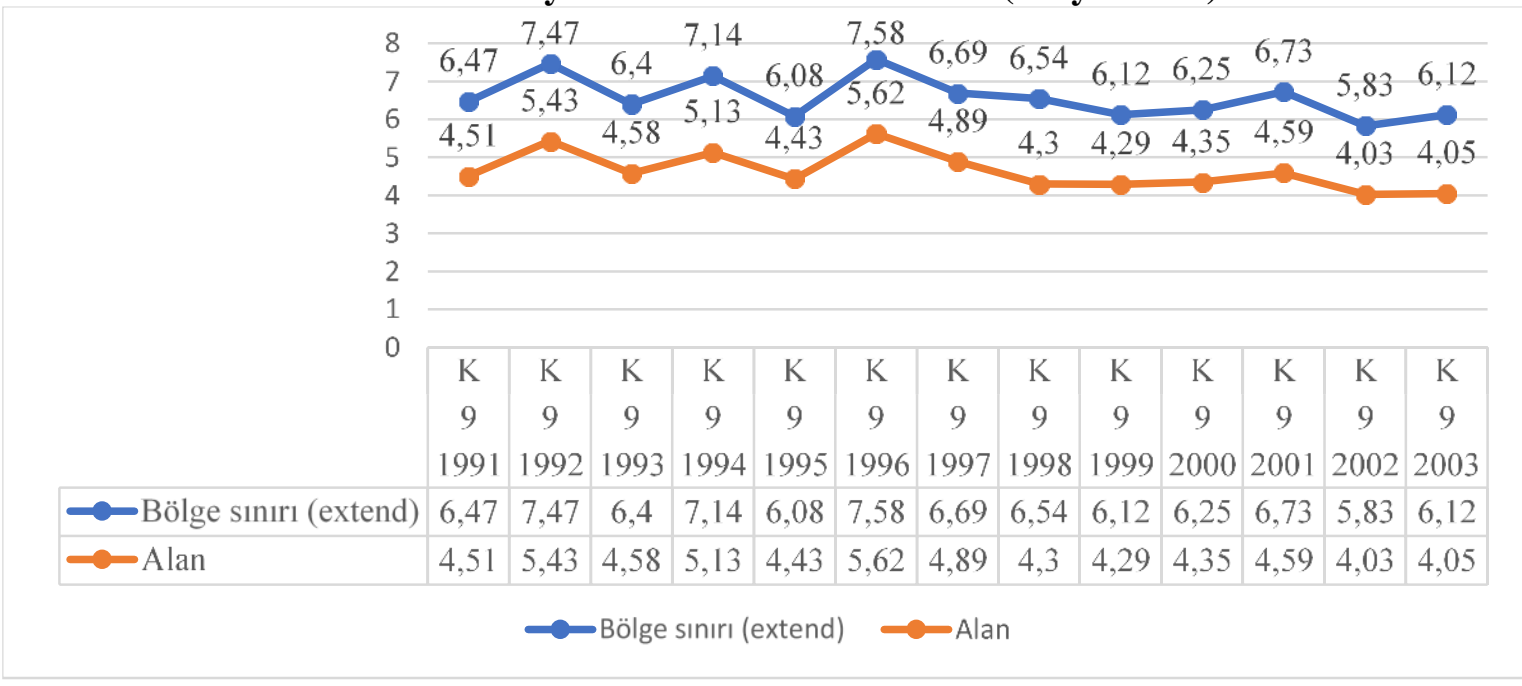

Kaynak: Grafik 4. Arctic Sea Ice Minimum | Vital Signs - Climate Change: Vital Signs of the Planet. (2020). NASA / Global Climate Change. https://climate.nasa.gov/vital-signs/arctic-sea-ice/'den elde edilen veriler ile düzenlenmiştir.

Grafik 5 verileri 2004-2019 y1llarını göstermektedir. 2004'te 5,98 milyon $\mathrm{km}^{2}$ 'ye düșen bölge sınırı değeri 2019'da 4,32 milyon $\mathrm{km}^{2}$ 'ye kadar düşmüştür. 2004'te 4,39 milyon km² 'ye çıkan alan değeri ise 1979'a göre çok büyük bir düşme yaparak 2019'da 3,13 milyon km² 'ye inmiştir. 


\section{Grafik 5. Kuzey Kutbu 2004-2019 Verileri (Milyon km²)}

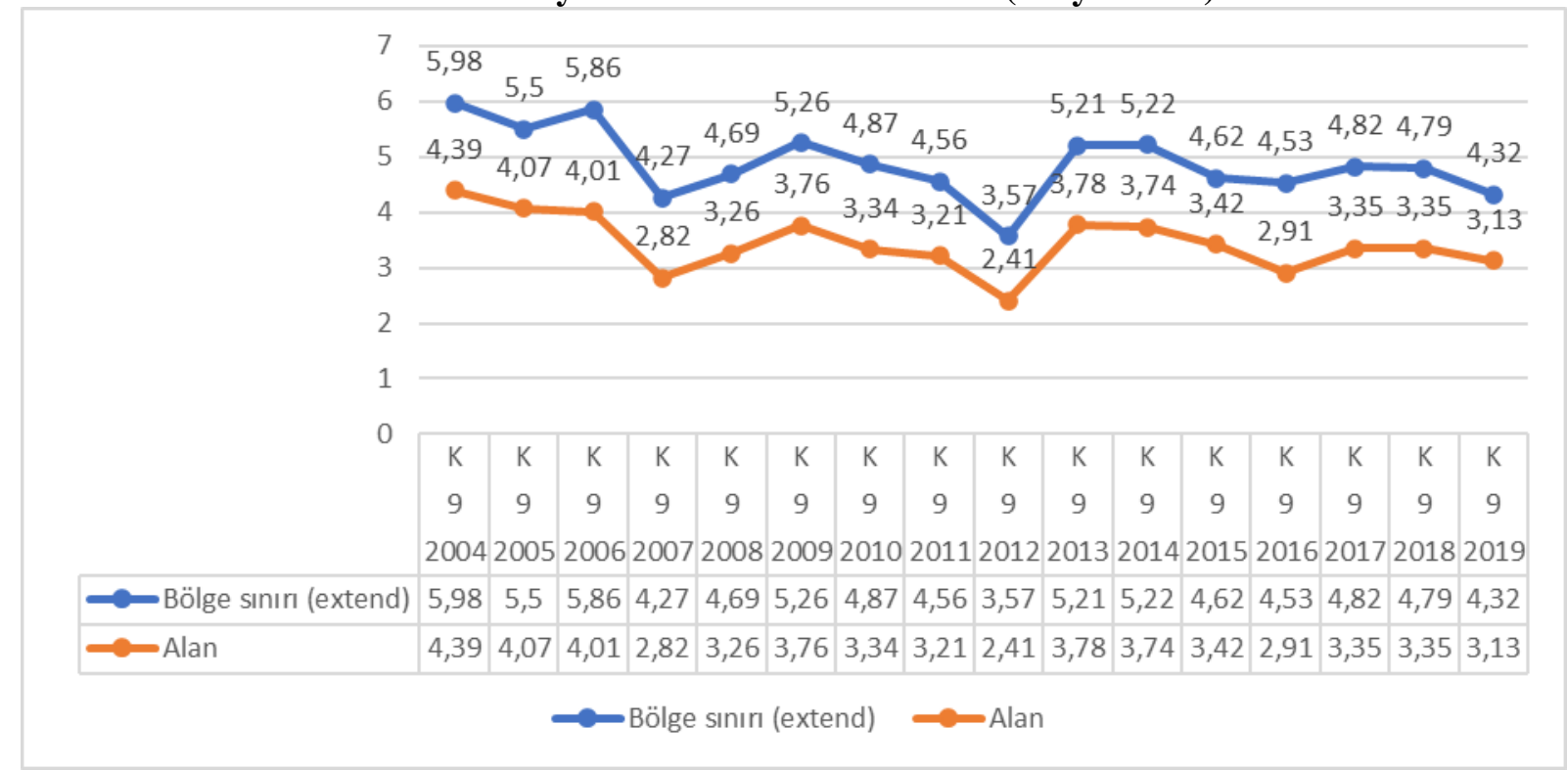

Kaynak: Grafik 5. Arctic Sea Ice Minimum | Vital Signs - Climate Change: Vital Signs of the Planet. (2020). NASA / Global Climate Change. https://climate.nasa.gov/vital-signs/arctic-sea-ice/ 'den elde edilen veriler ile düzenlenmiştir.

1979-2019 yıllarını kapsayan Grafik 3, Grafik 4 ve Grafik 5 verilerinde görüldüğü gibi, Kuzey Kutbu'nda son 40 yıl içinde bölge sınırı değerlerinde $-2,73$ milyon $\mathrm{km}^{2}$ ve alan değerinde 1,45 milyon $\mathrm{km}^{2}$ değer kaybı olmuştur. Yüzdesel olarak ifade edildiğinde ise 1979-2019 yılları arasında her on yıldaki yüzdesel kayıp oranı \%12,85'tir. Grafik 6'da ise bu buz kütlelerindeki incelmenin nasıl 1979'dan itibaren baş aşağı bir ivme ve hızla azaldığı görülmektedir.

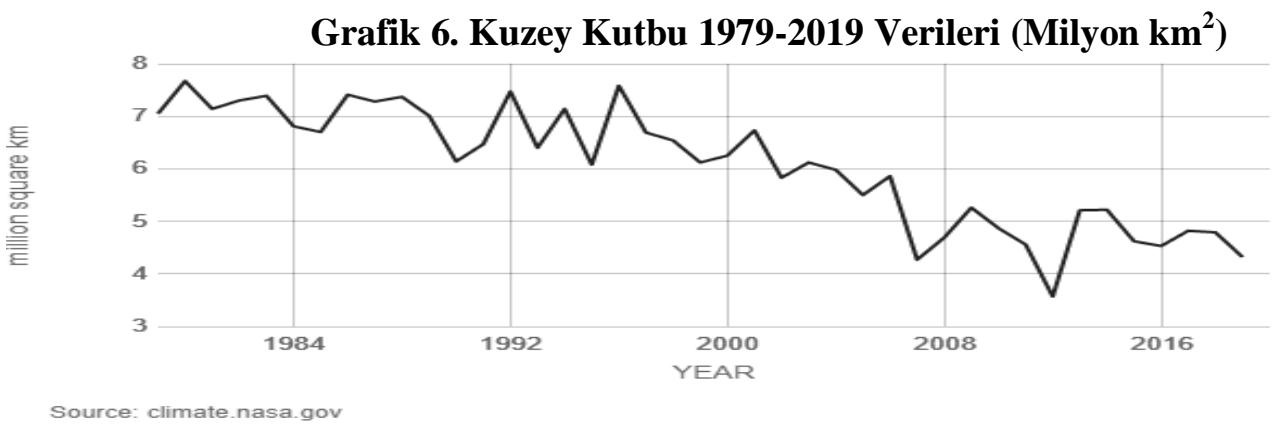

Kaynak: Grafik 6. Arctic Sea Ice Minimum | Vital Signs - Climate Change: Vital Signs of the Planet. (2020). NASA / Global Climate Change. https://climate.nasa.gov/vital-signs/arctic-sea-ice/ 'den elde edilen veriler ile düzenlenmiştir.

Yukarıdaki grafiklerde yer alan verilere göre çizilen Kuzey Kutbu buzul erimesinin coğrafik konum ile görsel olarak Harita 1, Harita 2 ve Harita 3 'te açıçca görülmektedir. ${ }^{3}$

\footnotetext{
3 1979-2019 yılları arasındaki değişimi video canlandırması ile görmek için bkz. Sea Ice 1979-2019- Climate Time Machine. (2020). NASA. https://climate.nasa.gov/interactives/climate-time-machine
} 
Harita 1. 1979 Y1lı Verilerine Göre Kuzey Kutbu

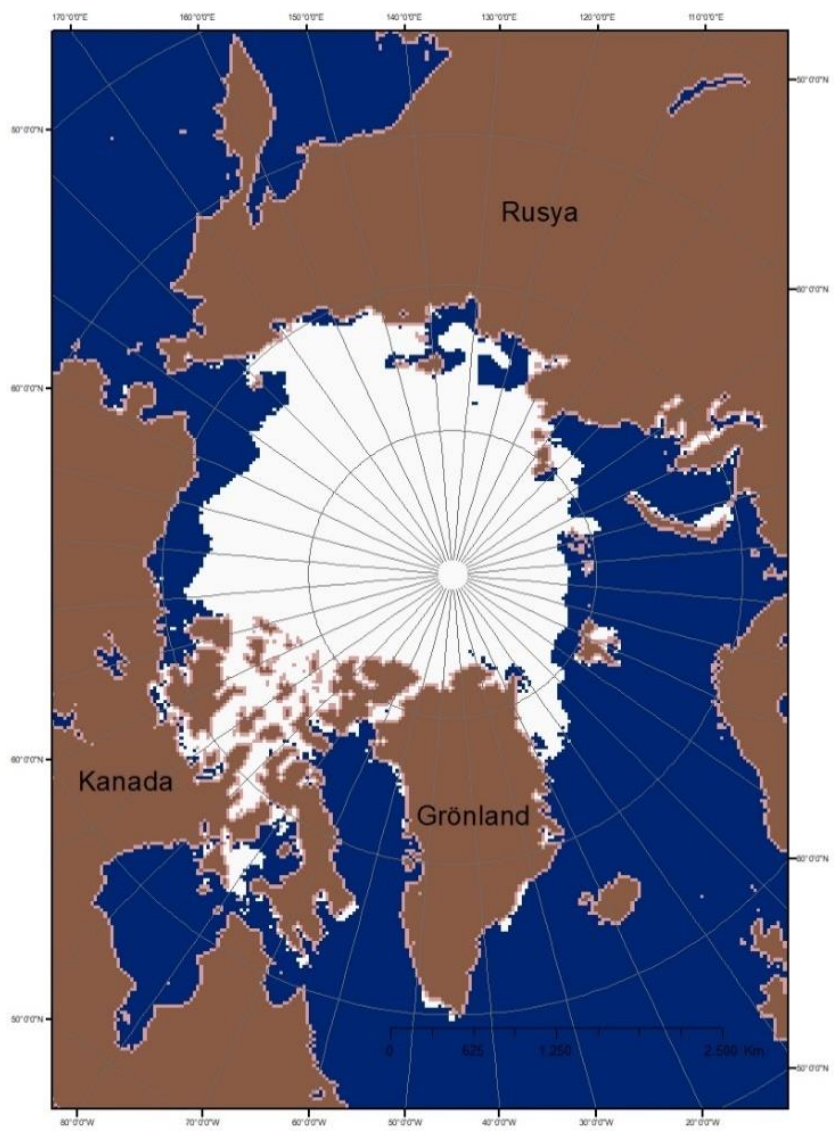

Kaynak: Harita 1 Sea Ice Index | National Snow and Ice Data Center. (2020, June). NSIDC. https://nsidc.org/data/seaice_index/ ; /DATASETS/NOAA/G02135/ dizini. (2020, June). Sidads.Colorado.Edu. ftp://sidads.colorado.edu/DATASETS/NOAA/G02135/ ; Arctic Sea Ice Minimum | Vital Signs - Climate Change: Vital Signs of the Planet. (2020). NASA / Global Climate Change. https://climate.nasa.gov/vital-signs/arctic-sea-ice/ 'den elde edilen veriler ile Zeynep Ortakavak tarafindan düzenlenmiştir.

1979 y1lina ait Harita 1'de Kuzey Kutbu NASA / Global Climate göre bölge sınırı (extend) 7,05 milyon $\mathrm{km}^{2}$ olarak hesaplanmıştır.
Change verilerine 
Harita 2: 1999 Yılı Verilerine Göre Kuzey Kutbu

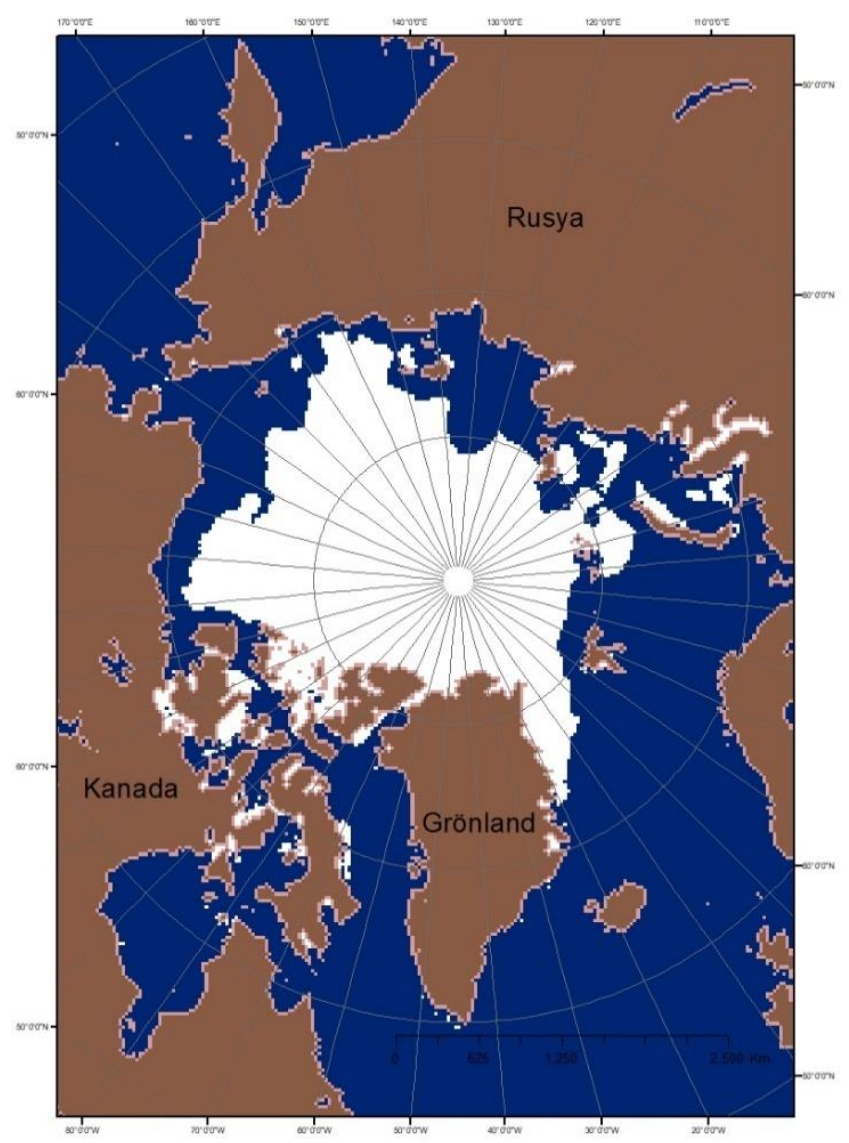

Kaynak: Harita 2 Sea Ice Index | National Snow and Ice Data Center. (2020, June). NSIDC. https://nsidc.org/data/seaice_index/; /DATASETS/NOAA/G02135/dizini. (2020, June). Sidads.Colorado.Edu. ftp://sidads.colorado.edu/DATASETS/NOAA/G02135/ ; Arctic Sea Ice Minimum|Vital Signs - Climate Change: Vital Signs of the Planet. (2020). NASA / Global Climate Change. https://climate.nasa.gov/vitalsigns/arctic-sea-ice/ 'den elde edilen veriler ile Zeynep Ortakavak tarafından düzenlenmiştir.

Harita 2'de 1999 yılı verilerine göre Kuzey Kutbunun alanını göstermektedir. Harita 2'de buzul erimesi açık bir şekilde ortaya çıkmaya başlamaktadır. 1999'da bölge sınırı (extend) 6,12 milyon $\mathrm{km}^{2}$ 'ye düşmektedir. 
Harita 3: 2019 Yılı Verilerine Göre Kuzey Kutbu

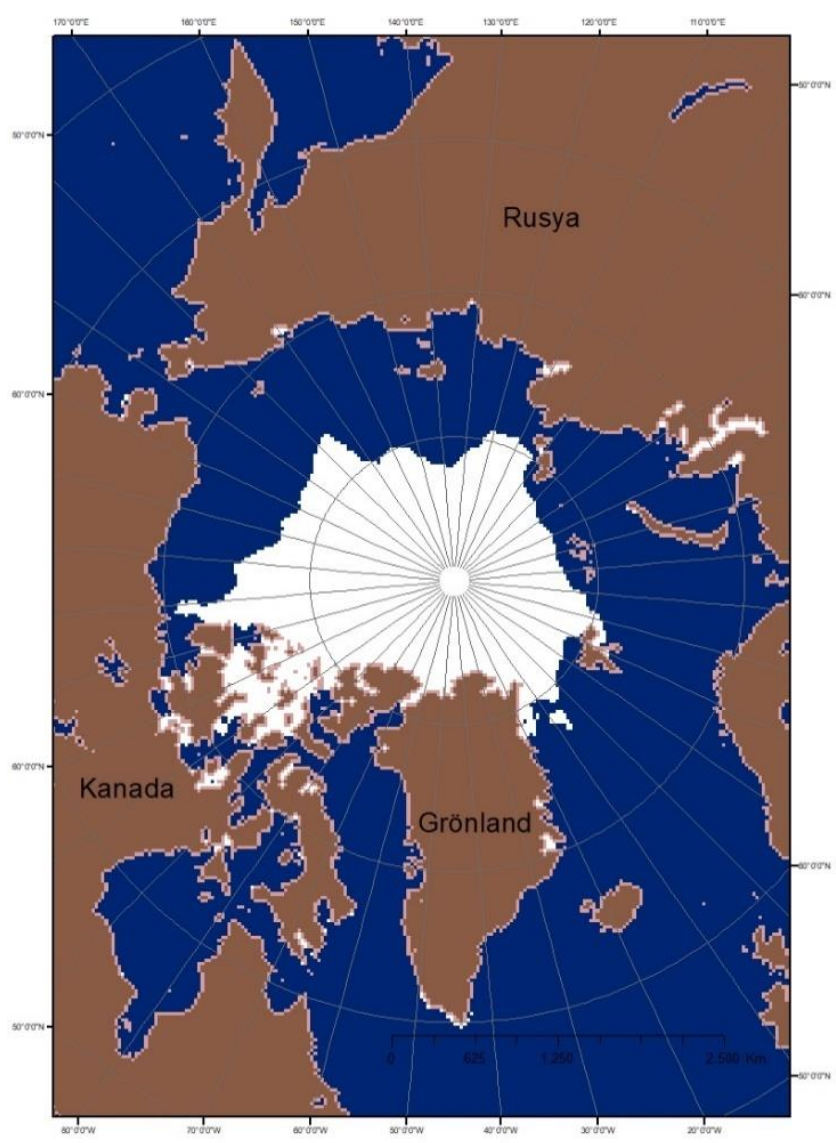

Kaynak: Harita 3 Sea Ice Index | National Snow and Ice Data Center. (2020, June). NSIDC. https://nsidc.org/data/seaice_index/; /DATASETS/NOAA/G02135/dizini. (2020, June). Sidads.Colorado.Edu. ftp://sidads.colorado.edu/DATASETS/NOAA/G02135/ ; Arctic Sea Ice Minimum | Vital Signs - Climate Change: Vital Signs of the Planet. (2020). NASA / Global Climate Change. https://climate.nasa.gov/vitalsigns/arctic-sea-ice/ 'den elde edilen veriler ile Zeynep Ortakavak tarafından düzenlenmiştir.

Harita 3’te Kuzey Kutbu bölge sınırının (extend) 4,32 milyon km²'ye düştüğü görsel olarak da çok açık ve net bir şekilde görülmektedir.

100 y1ll1k bir dönemi alan Resim 1'de ise, 2000, 2010-2030, 2040-2060 ve 2070-2090 y1llar1 arasındaki Kuzey Kutbu buzul alanlarının erimesi açık bir şekilde görülmektedir. Resim 1'de aynı zamanda erime ile ortaya çıkan toprak alanlarda gözükmektedir. 2000 yılında başlayan bu yayılma durumu 2100 y1lında tüm bölgeyi kaplayacaktır (Durand, 2006: 12). 
Resim 1: Kuzey Kutbu 2000-2090 Yılları Arasında Buzul Erimesi

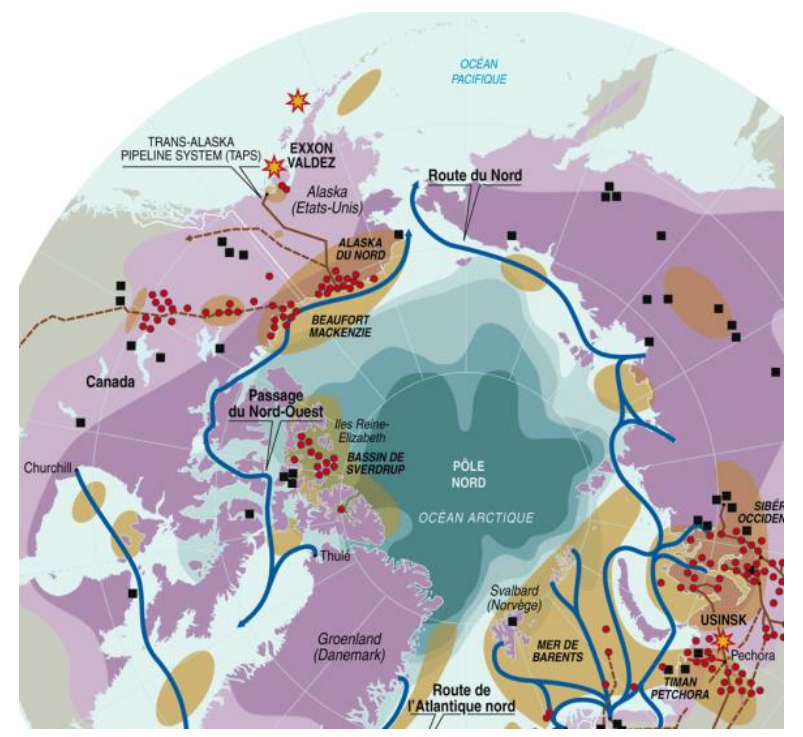

Kaynak: Durand, F. (2006). Accélération de la fonte des pôles Nord et Sud. Le Monde Diplomatique, 12-13. https://www.monde-diplomatique.fr/publications/1_atlas_geopolitique/a53302

Kuzey Kutbu'ndaki hava sıcaklığı artmasının kuzey buzullarını erimesine yol açmaktadır. Hava sıcaklığının artması ile buzul erimesindeki korelasyonu ortaya koyan Resim 2'de Frédéric Duran'ın NASA verileri ile düzenlediği senaryoda 2050 yılına kadar $-1,2$ 'dan $-0,4$ 'e, $-0,4$ 'ten $+0,4$ 'e, $+0,4$ 'ten $+1,2$ 'ye, $+1,2$ 'den +2 'ye, +2 'den $+2,8$ 'e, $+2,8$ 'den $+3,6$ 'ya ve $+3,6$ 'dan daha fazla hava sıcaklığı artış senaryoları yer almaktadır (Durand, 2006).

\section{Resim 2: 2050 Yılına Kadar Kuzey Kutbunda Hava Sıcaklığı Artış Senaryosu}

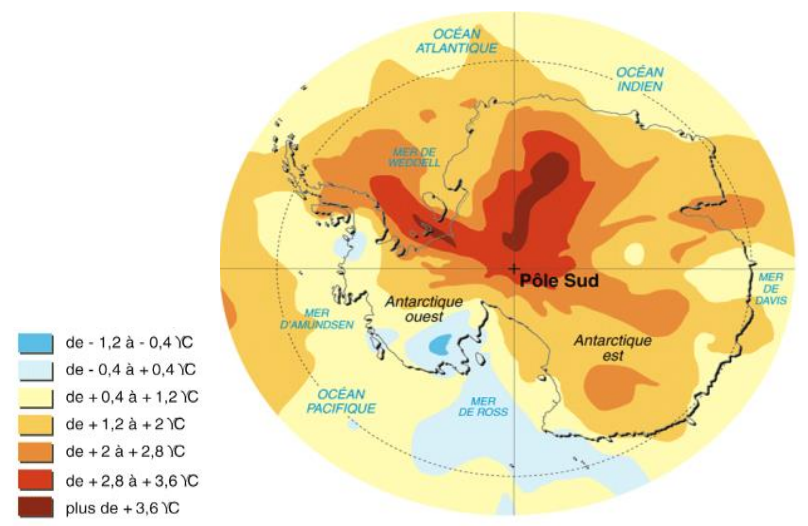

Kaynak: Durand, F. (2006). Accélération de la fonte des pôles Nord et Sud. Le Monde Diplomatique, 12-13. https://www.monde-diplomatique.fr/publications/1_atlas_geopolitique/a53302 


\section{Deniz Seviyesinin Yükselmesinin Ülkelerin Egemenlik Haklarına "De Facto" Etkisi}

Buzulların erimesi problemi sadece küresel ısınma ve küresel ısınmaya bağlı çölleşme değil aynı zamanda öncelikli olarak küresel boyutta insanlığın karşı karşıya kaldığı deniz seviyelerinin yükselmesi sorunudur. Bu sorun doğrudan doğruya ülkelerin yaşam, üretim, tarım, turizm ve kültürel doğal güzellikleri ve miraslarını tehdit etmektedir. Bu durum aynı zamanda ülkelerin sahip oldukları ve üzerinde egemenlik hakları olan yüzölçümlerinin doğal afet yolu ile "de facto" kaybolması anlamına gelmektedir. Dünya örnekleri arasında aşağıda sıralanan ve veri banklarından alınan uydu görüntülerinin Arcgis CBS programı ile düzenlendiği haritalarda bu somut olay daha açık bir şekilde görülmektedir. Örnek haritalarda deniz seviyesinin 1 metre ve 5 metre yükselme durumundaki senaryolar yer almaktadır.

\section{Hollanda Örneği}

Harita 4'te deniz seviyesinin 1 ve 5 metre yükselme durumlarında Hollanda'nın belli alanlarının su altında kaldığı görülmektedir. $41.453 \mathrm{~km}^{2}$ yüzölçümü olan Hollanda toprakları 1 metre su altında kaldığında, \%34,7 ve 5 metre su altında kaldığında ise \%46,2 oranında kayba uğrayacaktır. $\mathrm{Bu}$ senaryo olasılıklarına göre, toprak kayb1 \%34,7 olduğunda yaklaşık 14,384 $\mathrm{km}^{2}$ ve \%46,2'ye ulaştığında ise yaklaşık 19,197 $\mathrm{km}^{2}$ 'ye eş değerde bir toprak egemenliği kaybının oluşması tahmin edilebilir. Egemenlik kaybı sadece toprak kaybı değil aynı zamanda sosyo-ekonomik değeri olan liman, sanayi, ticari, turizm, eğitim tesislerinin ve kişisel ve kurumsal mülklerin kaybı anlamına gelmektedir. Aynı zamanda doğal güzellik olarak adlandırılan nehir, göl, delta, koy, körfez ve kumsal alanları ve deniz flora ve faunasının bozulması ve yok olmasına anlamına da gelmektedir.

Harita 4: Deniz Seviyesinin 1 ve 5 Metre Yükselmesi Durumunda Hollanda
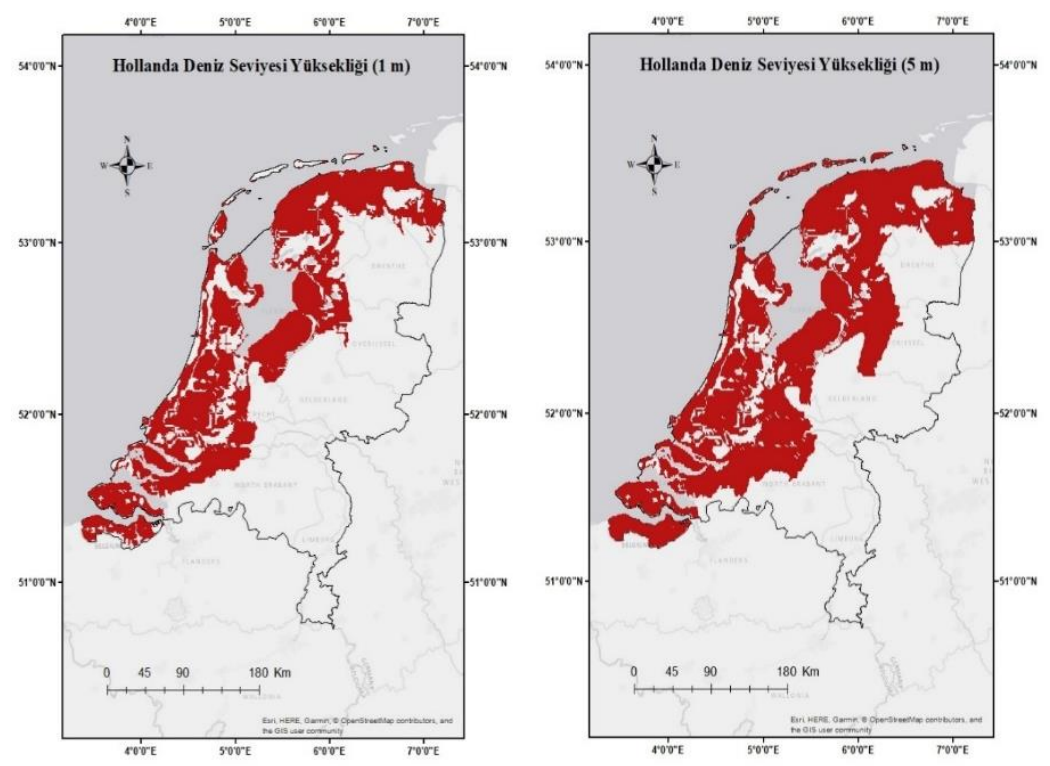

Kaynak: Harita 4 Maps \& GIS Data ( Northern Europe) . (2020, June). Center for Remote Sensing of Ice Sheets (CRESIS). https://cresis.ku.edu/content/research/maps ; GADM. (2020, June). GADM. https://gadm.org/data.html 'den elde edilen veriler ile Zeynep Ortakavak tarafından düzenlenmiştir.

Trilyonca dolarlık ekonomik kaybın yanı sıra, Hollanda'nın nüfusunun 2019 verilerine göre 17,3 milyon olduğu göz önüne alınırsa, 1 metre su yükselmesi durumunda. $41.453 \mathrm{~km}^{2}$ 'lik bir alan üzerinde yaşayan bu nüfusun yaklaşık 6 milyonu genel olarak etkilenecektir. Ancak, kıy1 bölgelerindeki şehirlerde daha yoğun bir nüfusun yaşadığı düşünülürse, bu rakam 6 milyonun çok daha üzerinde olacaktır. 5 metre senaryosunda ise Hollanda nüfusunun $22.256 \mathrm{~km}^{2}$ lik bir alanda 
kalacağ1 düşünülebilir. Böyle bir durumda, Hollanda'nın gelecek nesilleri Almanya, Fransa gibi veya Avrupa'nın aşağı kısımlarında bulunan başka ülkelerine ya da başka kıtalara göç etmek zorunda kalabilir.

\section{Bangladeş Örneği}

Bangladeş'in 147,570 km² yüz ölçümü bulunmaktadır. Bangladeş, Avrupa ülkeleri ile karşılaştırıldığında yüzölçümü küçük fakat nüfusu çok fazla bir ülkedir. Bu büyük nüfus bir anlamda dar bir yüz ölçümü üzerinde yaşamaktadır. Belli aralıklar ile tropikal tayfun ve sel felaketlerini yaşayan ülke nüfusunun çoğunluğu her zaman bu olumsuzluklardan etkilenmektedir. 2018 verilerine göre Bangladeș nüfusu 161,4 milyondur.

Harita 5: Deniz Seviyesinin 1 Metre ve 5 Metre Yükselmesi Durumunda Bangladeş

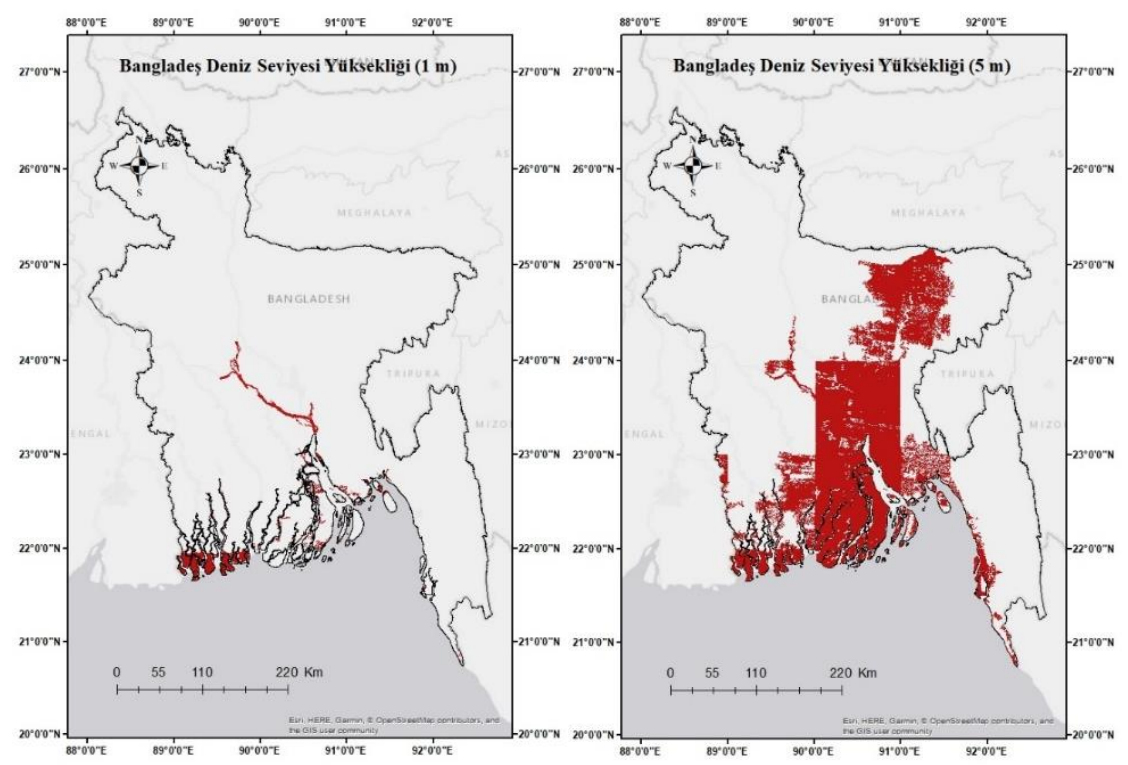

Kaynak: Harita 5 Maps \& GIS Data ( Northern Europe) . (2020, June). Center for Remote Sensing of Ice Sheets (CRESIS). https://cresis.ku.edu/content/research/maps ; GADM. (2020, June). GADM. https://gadm.org/data.html 'den elde edilen veriler ile Zeynep Ortakavak tarafindan düzenlenmiştir.

$\mathrm{Bu}$ senaryo olasılıklarına göre Bangladeş'in 1 metre sular altında kalması durumunda topraklarının \%1,9'u 5 metre sular altında kalması durumunda ise $\% 25,8$ 'i kaybolacaktır. 5 metre senaryosunda Bangladeş $38.073 \mathrm{~km}^{2}$ lik bir toprak kaybına uğrayacaktır. 147,570 km² bir alan üzerinde yaşayan ülke nüfusu etkilenecektir. Ancak, kıyı bölgelerindeki şehirlerde daha yoğun nüfusun yaşadığı düşünülürse, bu bölgelerdeki nüfus daha fazla etkilenecektir. Kilometre kareye düşen kişi sayısı açısndan, 1 metrede 3 milyon ve 5 metrede 41 milyon civarında insanın etkilenmesi beklenirken, kıyı bölgelerinde etkilenen nüfus senaryo tahmininden çok daha fazla olacaktır.

\section{Vietnam Örneği}

Vietnam’ın $331.212 \mathrm{~km}^{2}$ yüz ölçümü bulunmaktadır. Vietnam, Güneydoğu Asya Çinhindi yarımadasının doğusunda yer alan orta büyüklükte bir ülkedir. Yüzölçümüne göre nüfusu çok fazla bir ülkedir. 2018 verilerine göre Vietnam nüfusu 95.5 milyondur. Bu senaryo olasıllklarına göre Vietnam'in 1 metre sular altında kalması durumunda topraklarını \%7,9'u ve 5 metre sular altında kalması durumunda ise \%13,6'lı bir alanın kaybolacağ tahmin edilebilir. $331.212 \mathrm{~km}^{2}$ bir alan üzerinde yaşayan bu nüfusun 95,5 milyonu bu olumsuzluklardan etkilenecektir. 
Harita 6: Deniz Seviyesinin 1 Metre ve 5 Metre Yükselmesi Durumunda Vietnam
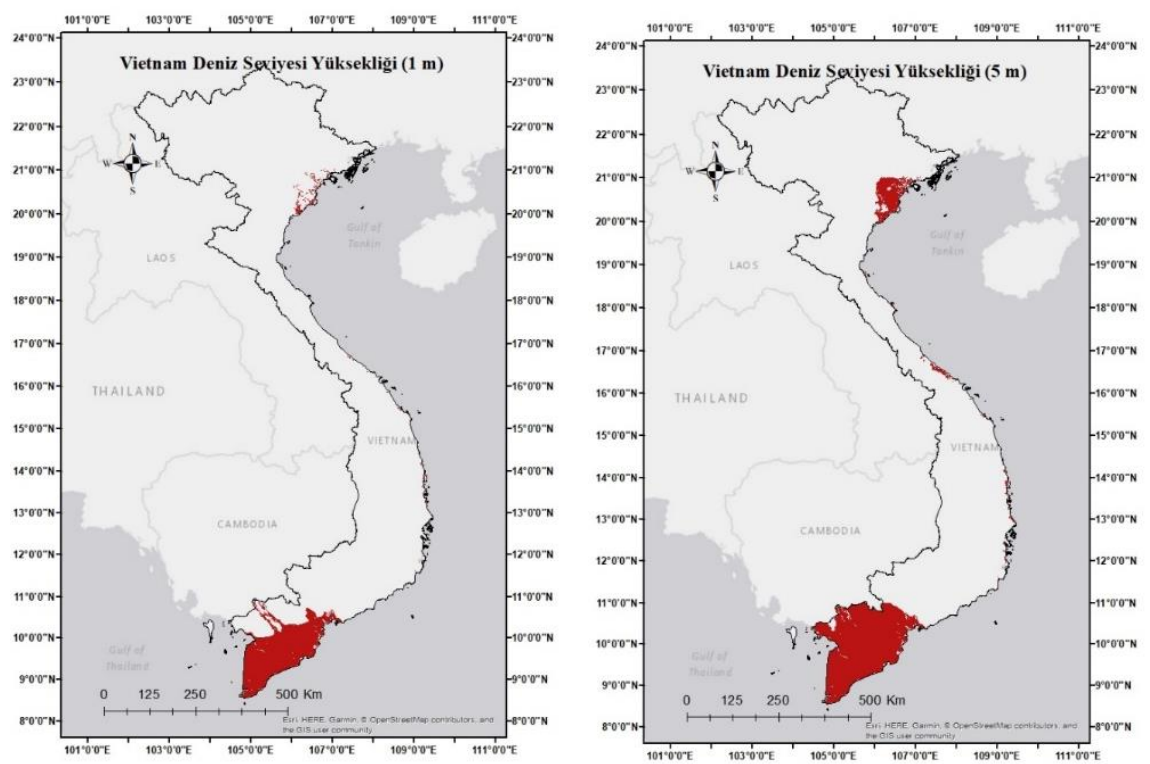

Kaynak: Harita 6 Maps \& GIS Data ( Northern Europe) . (2020, June). Center for Remote Sensing of Ice Sheets (CRESIS). https://cresis.ku.edu/content/research/maps ; GADM. (2020, June). GADM. https://gadm.org/data.html 'den elde edilen veriler ile Zeynep Ortakavak tarafından düzenlenmiştir.

Ancak, kıyı bölgelerindeki şehirlerde yaşayan nüfusun çok daha yoğun olduğu düşünülürse, bu rakamın 1 metrede 7,5 milyon ve 5 metrede 13 milyon civarında veya çok daha fazla olması olas1lık dahilinde bulunmaktadır. 5 metre senaryosunda Vietnam'ın $45.044 \mathrm{~km}^{2}$ 'lik bir toprak kaybına uğraması tahmin edilebilir. Böyle bir durumda, Vietnam'ın sosyo-ekonomik kaybı da büyük olacaktır. Tarım ve balıkçılık alanları, limanları ve sanayi tesisleri yok olacaktır.

\section{Pasifik Ada Devletleri Örneği}

Diğer taraftan buzul erimelerine bağlı deniz seviyesindeki yükselmesini en çok Pasifik ada devletlerini etkileyeceği hesaplanmaktadır. Böyle bir durumda aşağıdaki haritalarda görüldüğü gibi, bölgede bulunan adaların büyük kısmı sular altında kalacaktır.

Deniz seviyesinin yükselmelerinden en çok Mikronezya, Marshal Adaları, Taburo, Bairiki, Howland Adaları, Tuvalu, Tokelau, Wallis ve Futuna, Tokeleau, Jarvis Adaları, Napari, Kiribati, Tonga, Niue, Cook Adaları, Fransız Polinezya, Port Vila, Fuji, Yeni Kaledonya, Vanuatu ${ }^{4}$, Yeni Kaledonya, Solomon Adaları ve Papua Yeni Gine sahil şeritleri ve Papua Yeni Gine'ye bağlı adaciklar (Google Haritalar, 2020) sular altında kalacaktır (Australian Bureau of Meteorology and CSIRO, 2011). ${ }^{5}$

\footnotetext{
4 Sayfa sınırlaması kapsamında, Fuji, Yeni Kaledonya, Vanuatu bölgelerine ilişkin haritalara bu çalışmada yer verilmemiştir.

${ }^{5} \mathrm{Bu}$ ülkelerin bazılarının Birleşmiş Milletler Örgütü üyesi olduğunu bazıların da başka ülkelerin toprak bütünlüğü altında olan özerk bölgeler olduğunu hatırlamak gerekmektedir.
} 


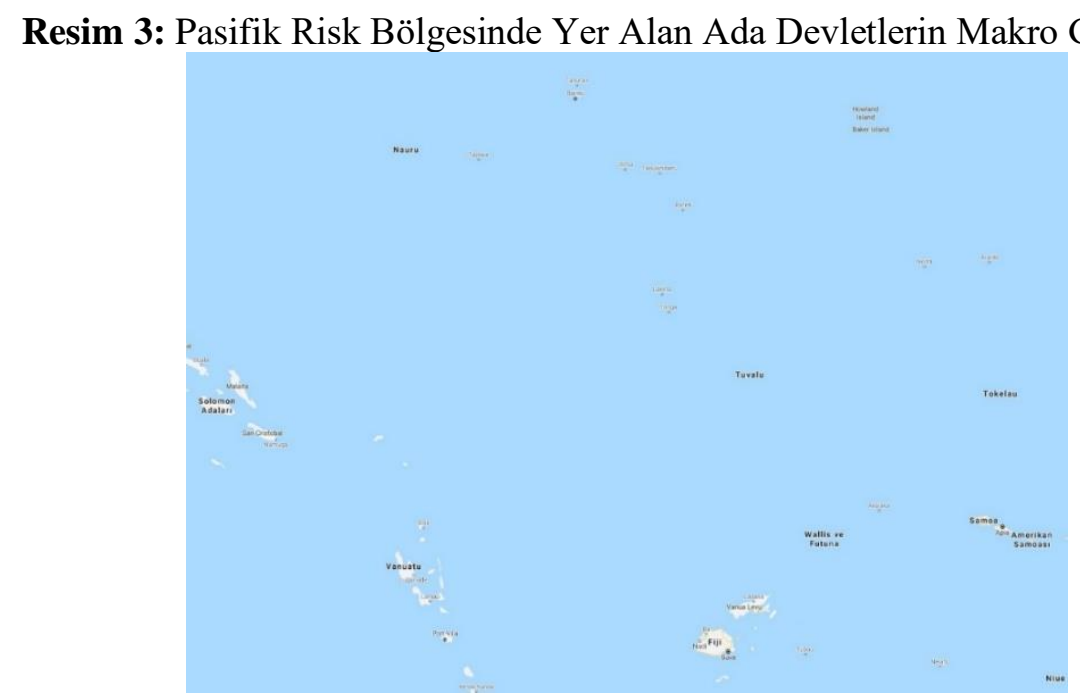

Kaynak: Google Haritalar. (2020, Haziran 26). Google Map. https://www.google.com.tr/maps/@ _ $12.4857516,173.5167713,5.25 z$

Resim 3'te görüldüğü gibi, Pasifik Okyanusu'nda Avustralya'nın doğusu ve Yeni Zelanda'nın kuzeyinde yer alan bu uçsuz bucaksız ve birleri ile deniz yolu bağlantıları yüzlerce ve binlerce deniz mili olan bu geniş alan üzerinde bulunan ada devletler ve adacıklar küresel ısınmaya bağlı ekolojik dengelerin bozulmasıyla oluşan buzul erimeleri sonucu ortaya çıkan deniz seviyelerindeki yükselmeden doğrudan doğruya etkilenecektir. Kimi volkanik adalar tamamen ortadan kalkmasa da etkilenecek bu adaların yerleşim birimleri olan sahil şeritleri ve sosyo-ekonomik alanları yok olacaktır. Bu örnekler içinde, yer alan Solomon Adaları'nda mevcut deniz seviyesinin yükselmesine bağlı balıkçık da zarar görmektedir. Kıyı köyleri boşaltılmak zorunda kalmaktadır (Watanabe, 2017). Örnek olarak yer verilen Solomon Adalarının ve Papua Yeni Gine adalarının acil durumları Australian Bureau of Meteorology and CSIRO (2011) yayınladığı raporda açık bir şekilde ortaya konmaktadır (Australian Bureau of Meteorology and CSIRO, 2011: 177, 206).

\section{Papau Yeni Gine ve Solomon Adaları Bölgesi Örneği}

Harita 7: Papau Yeni Gine ve Solomon Adaları Bölgesi

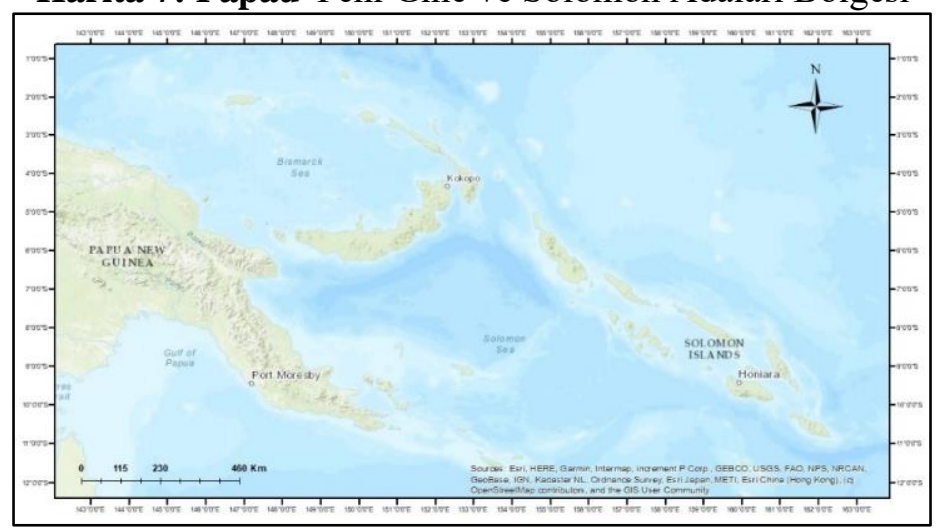

Kaynak: Harita 7 Maps \& GIS Data (Northern Europe). (2020, June). Center for Remote Sensing of Ice Sheets (CRESIS). https://cresis.ku.edu/content/research/maps; GADM. (2020, June). GADM. https:/gadm.org/data.html 'den elde edilen veriler ile Zeynep Ortakavak tarafindan düzenlenmiştir. 
Harita 7 bölgenin halihazırdaki konumunu ve yerini göstermektedir. Harita 8'de deniz seviyesinin 1 metre ve 2 metre yükselme durumunda adaların sular altında kalacağı kısımlar görülmektedir. Solomon Adaları 990 adadan oluşan bir ada devlet topluluğudur. Toplam yüzölçümü $28.450 \mathrm{~km}^{2}$ 'dir. Ancak ülke halihazırda 1 ve 2 metre senaryolarının dışında zaten deniz seviyesinden yükselme sorununu an ve an yaşamaktadır. Papau Yeni Gine ve Solomon Adaları Bölgesi 1 ve 2 metre senaryoları gösterilmiştir.

Harita 8: Papau Yeni Gine ve Solomon Adaları Bölgesi Deniz seviyesinin 1 Metre ve 2 Metre Yükselme Senaryosu

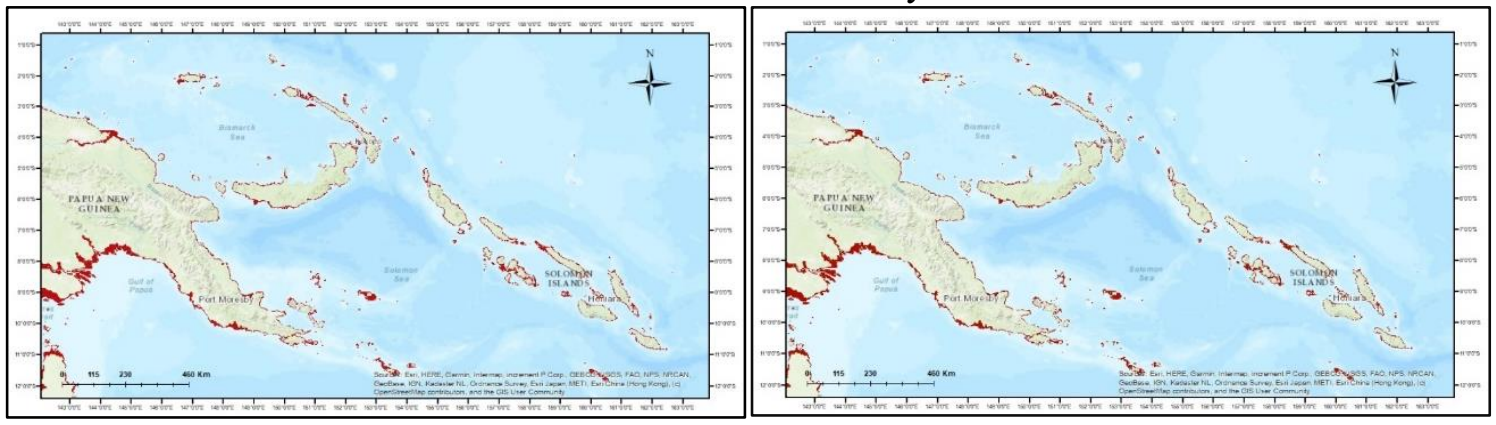

Kaynak: Harita 8 Maps \& GIS Data (Northern Europe). (2020, June). Center for Remote Sensing of Ice Sheets (CRESIS). https://cresis.ku.edu/content/research/maps ; GADM. (2020, June). GADM. https:/gadm.org/data.html 'den elde edilen veriler ile Zeynep Ortakavak tarafindan düzenlenmiştir.

Harita 8 'de deniz seviyesinin 1 ve 2 metre yükselme durumunda adaların sular altında kalacağ1 kısımlar görülmektedir. Ancak Harita 8'de her iki senaryo karşılaştırıldığında deniz seviyesindeki yükseklik farkının çok açık bir şekilde görülmemesi adaların volkanik ve yüksek irtifalı adalar olmasından kaynaklanmaktadır.

\section{Deniz Seviyesinin Yükselmesi Durumunda Tehdit Altında Bulunan Bazı Metropoliten Şehirlerden Örnekler}

Doğal olarak deniz seviyelerinin yükselmesi belli ülkeleri kısa, orta ve yakın gelecekte tehdit ettiği gibi, aynı zamanda kültürel miras ve cazibe merkezi olan şehirleri de etkileyecektir. Bu örnekler arasında, çalışmanın sınırlılığı kapsamında iki örnek verilmiştir. Bu örneklerden biri kıta Avrupa'sından Venedik ve diğer şehir örneği ise Kuzey Amerika kıtasından Miami'dir. Bu iki örnek aynı zamanda coğrafik olarak her iki kıtada görülecek deniz seviyesinin yükselmesini somut örnek ile göstermek için verilmiş̧ir. Venedik örneği doğal olarak İtalya'nın diğer Akdeniz kıyı yerleşim birimlerini ve diğer Akdeniz'e komşu olan ülke ve bölgeleri de etkilemiş olacaktır. Yine aynı şekilde, Miami örneği, bölgedeki, Bahama Adaları, Küba, Jamaika, Haiti, Dominik Cumhuriyeti, Porto Riko, Barbados, Grenada gibi, ada devletler ve Meksika Körfez kıyılarının da belli oranlarda etkilemesine emsal teşkil edecek bir bölgede bulunmaktadır.

\section{Venedik Örneği}

Harita 9'da yer alan senaryoya göre 1 metre yükselen deniz seviyesi Venedik şehrinin \%20,9'unu sular altında bırakacaktır. Harita 10'da yer alan diğer senaryoya göre buzulların erimesiyle deniz seviyesinin 5 metre yükselme durumunda, Venedik şehrinin \% 76,5'nin sular altında kalma riski bulunmaktadır. Her iki senaryoda da Venedik şehrinin tarihi ve kültürel dokusu ve şehir insanları zarar görecektir. 
Harita 9: Deniz Seviyesinin 1 Metre ve 5 Metre Yükselmesi Durumunda Venedik

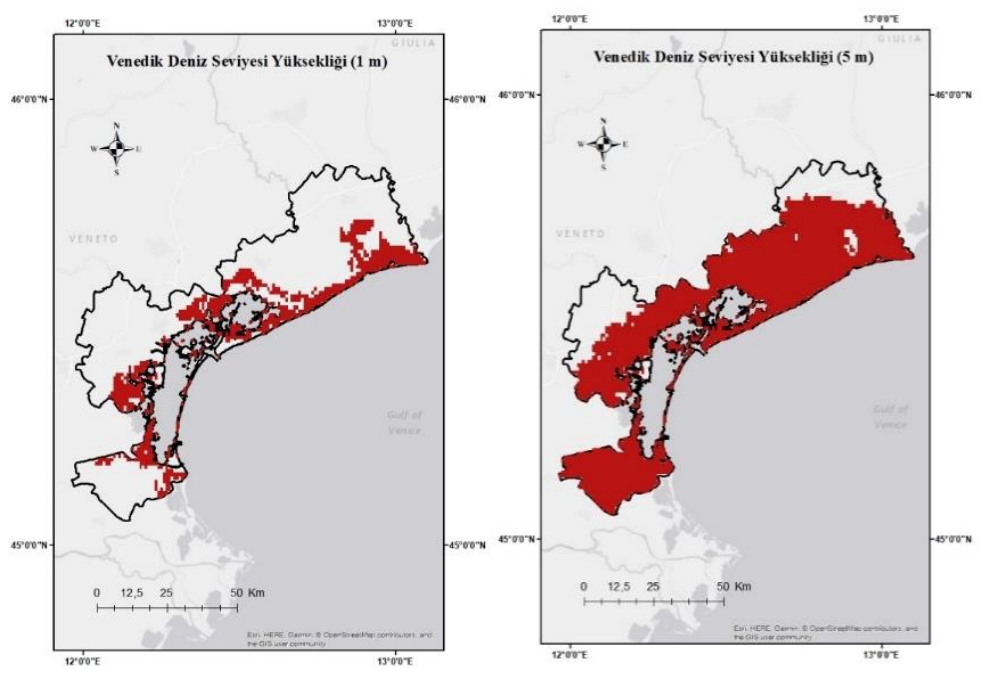

Kaynak: Harita 9 Maps \& GIS Data (Northern Europe) . (2020, June). Center for Remote Sensing of Ice Sheets (CRESIS). https://cresis.ku.edu/content/research/maps ; GADM. (2020, June). GADM. https:/gadm.org/data.html 'den elde edilen veriler ile Zeynep Ortakavak tarafindan düzenlenmiştir.

Harita 9'da yer alan birinci senaryoya göre 1 metre yükselen deniz seviyesi Venedik şehrinin $\% 20,9$ 'unu sular altında bırakacaktır. İkinci diğer senaryoya göre buzulların erimesiyle 5 metre yükselen deniz seviyesi Venedik şehrinin \%76,5'unu sular altında bırakma riski taşımaktadır. Her iki senaryoda da Venedik şehrinin tarihi ve kültürel dokusu ve şehir insanları zarar görecektir.

\section{Miami Örnĕgi}

Miami'de deniz seviyesi her gün artmaktadır. Uzmanlara göre de yüzyll içinde bütün şehir sular altında kalacaktır. Buna rağmen küresel 1sınmaya ilişkin toplum bilinci sorgulanmaktadır (Raim, 2020:4-5). Resim 4'te görülen Miami Risk haritasında Miami'nin deniz seviyesinin 1 metre yükselmesi durumunda risk altında bulunan kıyı şeritleri ve yerleşim birimleri görülmektedir.

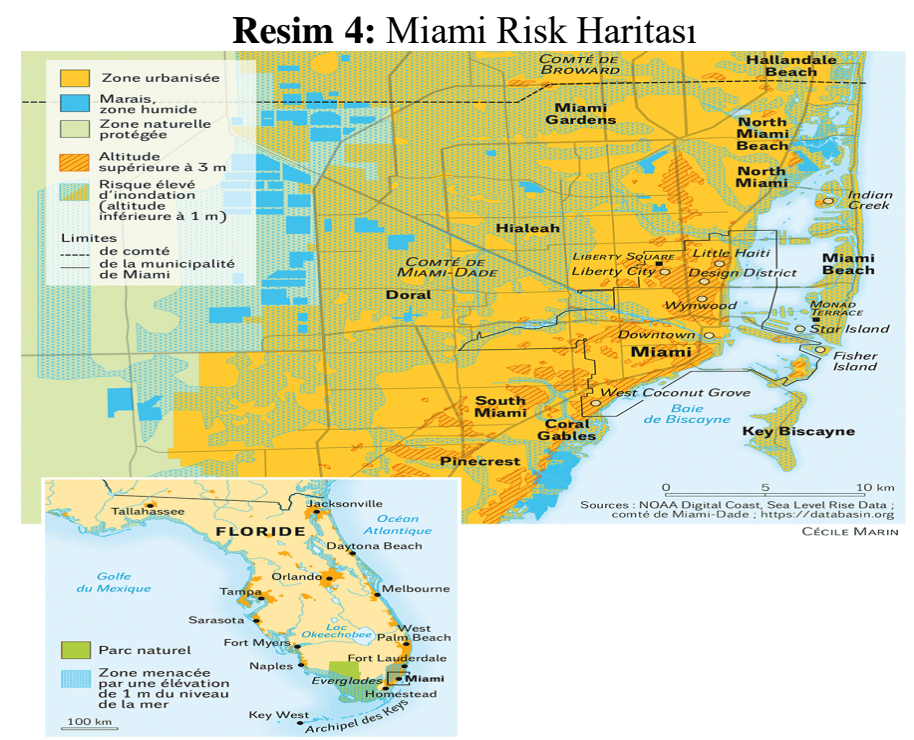

Kaynak: Marin, C. (2020, May). Montée des eaux à Miami. Le Monde diplomatique. https://www.mondediplomatique.fr/cartes/inondation-miami 
Harita 10'da Miami'nin deniz seviyesinin 1 metre artması durumundaki tahmin senaryo edilen senaryoya göre, bölgenin \%11,8'i sular altında kalacaktır. Harita 10' daki diğer senaryoya göre Miami’nin deniz seviyesinin 5 metre artması durumunda bölgenin \%98,7'si sular altında kalacaktır.

Harita 10: Deniz Seviyesinin 1 Metre ve 5 Metre Yükselmesi Durumunda Miami

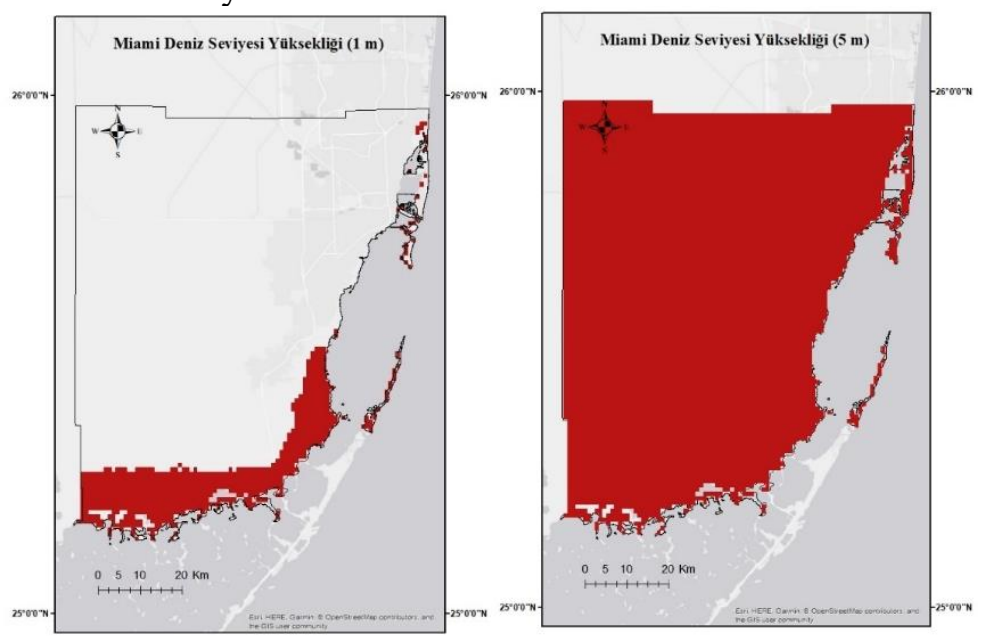

Kaynak: Harita 10 Maps \& GIS Data (Northern Europe). (2020, June). Center for Remote Sensing of Ice Sheets (CRESIS). https://cresis.ku.edu/content/research/maps ; GADM. (2020, June). GADM. https:/gadm.org/data.html 'den elde edilen veriler ile Zeynep Ortakavak tarafindan düzenlenmiştir.

Bu çalışma kapsamında yukarıda yer alan tüm senaryo haritalarında görüldüğü gibi, özellikle buzul erimesine bağl1 olarak örnek verilen ülkeler ve Venedik ve Miami gibi şehirler senaryodan öte önümüzdeki 100 yıl içinde Kutuplardaki buzul erimelerine bağlı deniz suyu seviyelerinin yükselme gerçeği ile karşı karşıya bulunmaktadırlar. Olay bir bakıma olasılık değil, tedbirler küresel ölçekte alınmadığg takdirde olabilirlik durumunu göstermektedir.

\section{Sonuç}

Doğa dışı faktörler ile atmosfere insan kaynaklı olarak yayılan sera gazları küresel ısınma yaratarak tetiklediği buzul erimesi sorunu eş zamanda dünyamızda deniz seviyelerin artmasına neden olmaktadır. Deniz seviyelerinin artması sorunu eğer onu tetikleyen buzul erimesi sorunu engellenmez ise devamlılığını sürdürecek bir problemdir. Bu problemin engellenmesi öncelikle, Kyoto Protokolü ve Paris İklim Antlaşması gibi antlaşmalarda belirtilen hususların dünya ülkelerinin tamamı tarafından sorumluluk alınmasıyla mümkün olabilecek acil bir konudur. Konunun acilliği ise tüm dünya ülkeleri nezdinde eşit bir şekilde önemsenmediği gibi küresel bazda duyulan kaygılar çok sınırlı kalmaktadır. ${ }^{6}$ Sorumlu olan ülkelerin küresel ısınma, buzul erimesi ve deniz seviyelerin artmasına yönelik tedbirler ve somut çözümler acilen uygulamaya konmalıdır. Ancak konuya olan önem vurgusu şimdilik zirve toplantılarında ve medya demeçlerinde birer retorik konuşmalar olarak kalmaktadır. Doğal olarak, ülkelerin sorumlulukları kapsamında tedbir almaları ve küresel 1sınmaya neden olan sanayi tesislerinin üretimlerinin kısılması veya hava kirli emisyonu engelleyen teknoloji kullanmalarının getireceği olağanüstü masraflardan kaçınır görünmektedirler. Oysa, küresel

\footnotetext{
${ }^{6}$ ABD’nin Kaliforniya eyaletinde olduğu marjinal bazı tedbirler ise günümüzde uygulanmaya yönelik acil eylem planları olmayıp, 15 veya 20 yıl sonrası yıllara yönelik siyasi açıklamalar ile sınırlı kalmaktadır. Bkz. Ohnsman, A. (2020, September 23). California Banning Sales Of New Gasoline Cars By 2035. Forbes. https://www.forbes.com/sites/alanohnsman/2020/09/23/california-banning-sales-of-new-gasoline-cars-in-the-state-by2035/\#7b9d53697b87
} 
boyuttaki küresel bir yıkım insanoğluna ve ülkelere çok daha pahalıya patlayacaktır. Hollanda, Bangladeş, Vietnam ve Pasifik ada devletleri ülke örnekleri ile Venedik ve Miami şehir örneklerinde görüldüğü gibi ülkelerin veya yerleşim birimlerinin 1 ve 5 metre sular altında kalması durumunda, yerleşik nüfus doğrudan etkilenecektir. Böyle bir durumda, yerleşik nüfuslar meydana gelecek bu doğa olayını canı, malı ile ödeyecek veya felaket öncesi acilen yeni yerleşim birimlerine toplu göç etme durumunda kalacaklardır. Küresel dünya laboratuvarında, dünya savaşları ve vekalet savaşları sonucu savaşlara bağlı zorunlu göç olaylarına tanık olan tarihten yapılacak bir çıkarsamayla deniz seviyelerinin artması gibi doğa olaylarına bağlı göçlerin yaratacağ sendrom, travma ve kaotik durumun savaş hallerindeki durumlar ile eş değerde görülmesi gerekmektedir. Özellikle küresel çapta mevcut olan küresel ısınma ve buzul erimesi problemlerine acilen gereken önemin alınması gerekmektedir.

\section{Kaynakça}

À la conquête des océans polaires. (2020, June). Le Monde Diplomatique. https://www.mondediplomatique.fr/cartes/conquete-oceans-polaires

Astrasheuskaya, N. (2012, December 13). Russia will not cut emissions under extended Kyoto climate pact - Reuters. Reuters. https://www.reuters.com/article/us-russia-kyoto/russia-willnot-cut-emissions-under-extended-kyoto-climate-pact-idUSBRE88C0QZ20120913

Australian Bureau of Meteorology and CSIRO (2011). Climate Change in the Pacific: Scientific Assessment and New Research | Volume 2: Country Reports : Chapter 11 Papua New Guinea The contributions of Kasis Inape from the Papua New Guinea National Weather Service and Maino Virobo from the Department of Env. https://www.pacificclimatechangescience.org/wp-content/uploads/2013/09/Volume-2country-reports.pdf

Baccaro, S. ve Descamps, P. (2020, April). Géopolitique du brise-glace. Le Monde Diplomatique, Avril 2020). https://www.monde-diplomatique.fr/2020/04/BACCARO/61587

Canada pulls out of Kyoto Protocol | CBC News. (2011, December 12). CBC, CBC News. https://www.cbc.ca/news/politics/canada-pulls-out-of-kyoto-protocol-1.999072

Carrington, D. (2020, June 17). Pandemics result from destruction of nature, say UN and WHO | World news | The Guardian. https://www.theguardian.com/world/2020/jun/17/pandemicsdestruction-nature-un-who-legislation-trade-greenrecovery?fbclid=IwAR1IDodAz_wkzxaLLlqUFBRrJGPO3m0cg6x81er2GQombUJ2WgYvNE18g4

Chemillier-Gendreau, M. (1998). Les enjeux de la conférence de Kyoto: Marchandisation de la survie planétaire. Le Monde Diplomatique.

Climate refugees in Bangladesh | DW Documentary - YouTube. (2019, March 20). DW. https://www.youtube.com/watch?v=co5uywe-1Z8

/DATASETS/NOAA/G02135/ dizini. (2020, June). Sidads. Colorado. Edu. ftp://sidads.colorado.edu/DATASETS/NOAA/G02135/

Durand, F. (2006). Accélération de la fonte des pôles Nord et Sud. Le Monde Diplomatique, 12-13. https://www.monde-diplomatique.fr/publications/1_atlas_geopolitique/a53302

Johansen, B. E. (2017). Climate Change: An Encyclopedia of Science, Society, and Solutions, (Volume I, Land and Oceans). ABC-CLIO, LLC.

GADM. (2020, June). GADM. https://gadm.org/data.html 
Google Haritalar. (2020, June 26). Google Map. https://www.google.com.tr/maps/@ $12.4857516,173.5167713,5.25 \mathrm{z}$

Il a fait $38^{\circ} \mathrm{C}$ en Sibérie : record de température au-delà du cercle arctique. (2020, June 22). Le Monde. https://www.lemonde.fr/planete/article/2020/06/22/il-a-fait-38-c-en-siberie-recordde-temperature-au-dela-du-cercle-arctique_6043746_3244.html

L'Atlas du Monde diplomatique. (2006). Armand Colin, Paris.

Land Reclamation in the Netherlands 1300 Vs 2000 - Brilliant Maps. (2017, July 2). Brilliant Maps. https://brilliantmaps.com/netherlands-land-reclamation/

Maps \& GIS Data (Northern Europe) . (2020, June). Center for Remote Sensing of Ice Sheets (CRESIS). https://cresis.ku.edu/content/research/maps

Marin, C. (2020, May). Montée des eaux à Miami. Le Monde diplomatique. https://www.mondediplomatique.fr/cartes/inondation-miami

Mathez, E. A. ve Smerdon, J. E. (2018). Climat Change: The Science of Global Warming and Our Energy Future (Second Edi). Columbia University Press.

Philander, S. G. (Ed.). (2012). Encyclopedia of Global Warming \& Climate Change (Second Edi). SAGE Publications.

Ohnsman, A. (2020, September 23). California Banning Sales Of New Gasoline Cars By 2035. Forbes. https://www.forbes.com/sites/alanohnsman/2020/09/23/california-banning-salesof-new-gasoline-cars-in-the-state-by-2035/\#7b9d53697b87

Radford, T. (2004, September 11). The drowned world . The Guardian. https://www.theguardian.com/science/2004/sep/11/meteorology.scienceofclimatechange

Raim, L. R. (2020, Mai). En Floride, les riches n'auront pas les pieds dans l'eau. Le Monde Diplomatique , 4-5. https://www.monde-diplomatique.fr/2020/05/RAIM/61762

Ramonet, I. (Juin-Juillet 2005). Espoirs écologiques. Manière de Voire, Ecologie:Le Grand Défi (81), 6-8.

René Dumont "Nous allons à l'effondrement total de notre planète» (1974)| Franceinfo INA YouTube. (2019, October 24). Ina Actu. https://www.youtube.com/watch?v=-Vb8MrZQK7g

René Dumont. (Octobre 1988). Une planète mise à sac: La survie de l'humanité en grand péril. Le Monde Diplomatique, 11-12.

Report of the United Nations Conference on the Human Environment. (1972). https://www.un.org/ga/search/view_doc.asp?symbol=A/CONF.48/14/REV.1

Report of the World Commission on Environment and Development: Our Common Future. (1987). https://sustainabledevelopment.un.org/content/documents/5987our-common-future.pdf

Sea Ice 1979-2019 - Climate Time Machine. (2020). NASA. https://climate.nasa.gov/interactives/climate-time-machine

Sea Ice Index | National Snow and Ice Data Center. (2020, June). NSIDC. https://nsidc.org/data/seaice_index/

The Paris Agreement | UNFCCC. (2015). United Nations Climate Change. https://unfccc.int/process-and-meetings/the-paris-agreement/the-paris-agreement

Total Greenhouse Gas Emissions / World Development Indicators | DataBank. (2020). The World Bank. 
Su Üzerine Dünya İnşa Etmek: Küresel Sistemde Ekolojik Faktöre Bağlı Olarak...

https://databank.worldbank.org/reports.aspx?source=2\&series=EN.ATM.GHGT.KT.CE\&c ountry=\#

Viviano, F. (2017, September). How the Netherlands Feeds the World. National Geographic. https://www.nationalgeographic.com/magazine/2017/09/holland-agriculture-sustainablefarming/

World Conversation Strategy : Living Resources Conservation for Sustainable Development. (1980). https://portals.iucn.org/library/efiles/documents/wcs-004.pdf

World Development Indicators | DataBank. (2020). The World Bank. https://databank.worldbank.org/reports.aspx?source=2\&series=EN.ATM.CO2E.PC\&count ry $=\#$

Written question - Withdrawal of Japan from the Kyoto Protocol - E-000290/2013. (2013, January 13). European Parliament. https://www.europarl.europa.eu/sides/getDoc.do?pubRef=//EP//TEXT+WQ+E-2013-000290+0+DOC+XML+V0//EN 